\title{
Diversity of Gain Modulation by Noise in Neocortical Neurons: Regulation by the Slow Afterhyperpolarization Conductance
}

\author{
Matthew H. Higgs, ${ }^{1}$ Sean J. Slee, ${ }^{1}$ and William J. Spain ${ }^{1,2,3}$ \\ Departments of ${ }^{1}$ Physiology and Biophysics and ${ }^{2}$ Neurology, University of Washington, Seattle, Washington 98105 , and ${ }^{3}$ Veterans Affairs Puget Sound \\ Health Care System, Seattle, Washington 98108
}

\begin{abstract}
Neuronal firing is known to depend on the variance of synaptic input as well as the mean input current. Several studies suggest that input variance, or "noise," has a divisive effect, reducing the slope or gain of the firing frequency-current $(f-I)$ relationship. We measured the effects of current noise on $f$-I relationships in pyramidal neurons and fast-spiking (FS) interneurons in slices of rat sensorimotor cortex. In most pyramidal neurons, noise had a multiplicative effect on the steady-state $f-I$ relationship, increasing gain. In contrast, noise reduced gain in FS interneurons. Gain enhancement in pyramidal neurons increased with stimulus duration and was correlated with the amplitude of the slow afterhyperpolarization (sAHP), a major mechanism of spike-frequency adaptation. The 5- $\mathrm{HT}_{2}$ receptor agonist $\alpha$-methyl-5-HT reduced the sAHP and eliminated gain increases, whereas augmenting the sAHP conductance by spike-triggered dynamic-current clamp enhanced the gain increase. These results indicate that the effects of noise differ fundamentally between classes of neocortical neurons, depending on specific biophysical properties including the sAHP conductance. Thus, noise from background synaptic input may enhance network excitability by increasing gain in pyramidal neurons with large sAHPs and reducing gain in inhibitory FS interneurons.
\end{abstract}

Key words: noise; gain; pyramidal neuron; interneuron; sAHP; coincidence detection

\section{Introduction}

To understand single-neuron computation, we must know how the rate and pattern of synaptic input influence output firing. Two aspects of input-output relationships in cortical neurons are well understood. First, we know that the frequency of excitatory synaptic input $(\mathrm{F})$ is encoded by the output firing frequency (f). The F-f relationship is approximated by the experimentally accessible firing frequency-current $(f-I)$ relationship, where $I$ is injected current, giving a first-order description of rate-to-rate coding. Second, it is clear that rapidly fluctuating input causes reproducible spike patterns (Mainen and Sejnowski, 1995), indicating the possibility of precise timing codes. In addition, neurons can encode input timing as the firing rate. Synchronizing subthreshold EPSCs can drive a neuron to firing threshold (Segundo et al., 1963), a phenomenon known as coincidence detection. Similarly, current noise that mimics random arrival of synchronized postsynaptic currents can increase the firing rate (Poliakov et al., 1996).

Received Nov. 4, 2005; revised July 10, 2006; accepted July 11, 2006.

This work was supported by a Veterans Affairs Merit Review to W.J.S. We thank Adrienne Fairhall for helpful discussions, Rodrigo Andrade for helpful suggestions on experimental technique, Christian Stricker and Robert Foehring for critical comments on previous versions of this manuscript, and Richard Lee and Carol Robbins for excellent technical assistance

Correspondence should be addressed to William J. Spain, Department of Neurology (127), 1660 South Columbian Way, Seattle, WA 98108. E-mail: spain@u.washington.edu.

DOI:10.1523/JNEUROSCI.1792-06.2006

Copyright $\odot 2006$ Society for Neuroscience $\quad$ 0270-6474/06/268787-13\$15.00/0
Although it is well known that neurons perform coincidence detection when the unsynchronized input is subthreshold, synchrony does not always increase the firing rate. In layer 5 pyramidal cells, synchronizing two groups of simulated EPSCs arriving at gamma frequency $(40 \mathrm{~Hz})$ increased the firing rate when each group was subthreshold but reduced the firing rate at higher input amplitude (Grande et al., 2004). Generally, a transition from coincidence detection to temporal integration may occur when the mean current exceeds threshold (Gerstner and Kistler, 2002). As a consequence, input synchrony or current fluctuation may lose its ability to raise the firing rate as the mean current increases. Consistent with this expectation, several studies of neocortical pyramidal neurons found that noise increased the firing rate primarily at low mean currents, reducing the gain of the $f-I$ relationship (Chance et al., 2002; Rauch et al., 2003; Shu et al., 2003) (but see Fellous et al., 2003). Thus, noisy "background" synaptic input may control the sensitivity of cortical neurons (Chance et al., 2002), providing a synaptic mechanism for multiplicative gain control thought to occur during processes such as attention (McAdams and Maunsell, 1999; Treue and MartinezTrujillo, 1999; Salinas and Thier, 2000). Gain modulation is thought to be an effect of the variance associated with background input, whereas the increase in average conductance causes a subtractive shift of the $f-I$ relationship (Holt and Koch, 1997; Chance et al., 2002).

In the present study, we investigated the effects of current noise on gain in pyramidal neurons and fast-spiking (FS) inter- 
neurons in the rat sensorimotor cortex. FS interneurons showed the expected transition from subthreshold coincidence detection to suprathreshold integration, causing noise to reduce gain. However, in most pyramidal neurons, the rate increase caused by noise grew across a range of currents from below threshold up to large currents that caused spike failure by depolarization block. Thus, noise increased gain. The gain increase was correlated with the slow afterhyperpolarization (sAHP) after a spike train, it was eliminated when the sAHP was reduced by a $5-\mathrm{HT}_{2}$ agonist, and it was enhanced when a spike-triggered dynamic-current clamp augmented the sAHP. These results suggest that a large sAHP conductance promotes suprathreshold coincidence detection and gain increases by noise in pyramidal neurons.

\section{Materials and Methods}

Preparation of cortical slices. Three- to 5-week-old Sprague Dawley rats were deeply anesthetized in a chamber filled with $5 \%$ sevoflurane in oxygen and quickly decapitated. A coronal hemisection of the cortex from $\sim 1 \mathrm{~mm}$ rostral to bregma to $4 \mathrm{~mm}$ caudal was removed from the left hemisphere, attached to the stage of a Vibratome tissue slicer (TPI, St. Louis, MO) using cyanoacrylate glue (Loctite 404; Loctite, Rocky Hill, $\mathrm{CT}$ ), and immersed in ice-cold cutting solution containing the following (in mM): 105 choline-Cl, $5 \mathrm{KCl}, 5 \mathrm{MgCl}_{2}, 26 \mathrm{NaHCO}_{3}, 1.25 \mathrm{NaH}_{2} \mathrm{PO}_{4}, 20$ tetraethylammonium- $\mathrm{Cl}, 20$ sucrose, $10 \mathrm{D}$-glucose, $1.3 \mathrm{Na}$-ascorbate, and 2.4 pyruvic acid. In some experiments, we used a more standard cutting solution containing the following (in $\mathrm{mm}$ ): 220 sucrose, $3 \mathrm{KCl}, 1$ $\mathrm{CaCl}_{2}, 5 \mathrm{MgCl}_{2}, 26 \mathrm{NaHCO}_{3}, 1.25 \mathrm{NaH}_{2} \mathrm{PO}_{4}$, and 10 D-glucose. Both cutting solutions were bubbled with $95 \% \mathrm{O}_{2} / 5 \% \mathrm{CO}_{2}$ to maintain $\mathrm{pH}$ at 7.4. Similar results were obtained with both solutions, so the results were pooled. Coronal slices ( $300 \mu \mathrm{m}$ thick) were cut, stopping rostral from the tip of the hippocampus, and transferred to a holding chamber filled with artificial CSF (ACSF) containing the following (in $\mathrm{mm}$ ): $130 \mathrm{NaCl}, 3 \mathrm{KCl}$, $2 \mathrm{CaCl}_{2}, 2 \mathrm{MgCl}_{2}, 26 \mathrm{NaHCO}_{3}, 1.25 \mathrm{NaH}_{2} \mathrm{PO}_{4}$, and 10 D-glucose, bubbled with $95 \% \mathrm{O}_{2} / 5 \% \mathrm{CO}_{2}$. The temperature of the holding chamber was maintained at $34^{\circ} \mathrm{C}$ for $30-60 \mathrm{~min}$ and then allowed to cool to room temperature.

Preparation of chick brainstem slices. In a small number of experiments, slices of embryonic day 20-21 chick brainstems were prepared as described by Slee et al. (2005).

Recording. A slice was transferred to a recording chamber mounted on the stage of an upright microscope (Zeiss, Thornwood, NY) and perfused at $\sim 2 \mathrm{ml} / \mathrm{min}$ with warmed ACSF $\left(34 \pm 1^{\circ} \mathrm{C}\right)$ prepared as described above. In some experiments, $\mathrm{CaCl}_{2}$ was reduced to $1.2 \mathrm{~mm}$ to approximate the physiological concentration in the cortex (Harris et al., 1981; Massimini and Amzica, 2001). Similar results were obtained with 2 and $1.2 \mathrm{mM} \mathrm{CaCl}_{2}$, so the data were pooled. For pharmacological experiments, the control recording solution also contained 6,7dinitroquinoxaline-2,3(1H,4H)-dione (DNQX) (20 $\mu \mathrm{M})$, ( \pm )-3-(2carboxypiperazin-4-yl)-propyl-1-phosphonic acid (CPP) $(5 \mu \mathrm{M})$, and picrotoxin $(100 \mu \mathrm{M})$ to block AMPA/kainate, NMDA, and $\mathrm{GABA}_{\mathrm{A}}$ receptors, respectively. Cells were visualized using infrared differential interference contrast optics. Whole-cell current-clamp recordings were obtained from cells located in the genu at the dorsal portion of the slice using an Axoclamp 2-A amplifier (Molecular Devices, Foster City, CA) in continuous bridge mode. The pipette solution contained the following (in mM): $127 \mathrm{KCH}_{3} \mathrm{SO}_{4}, 10$ myo-inositol, $2 \mathrm{MgCl}_{2}, 5 \mathrm{KCl}, 10 \mathrm{HEPES}, 0.02$ EGTA, $6 \mathrm{Na}_{2}$ phosphocreatine, $2 \mathrm{Na}_{2} \mathrm{ATP}$, and $0.5 \mathrm{Na}_{3} \mathrm{GTP}$, pH 7.2-7.3. In some experiments, the pipette solution also contained $0.5 \%$ biocytin for subsequent visualization of recorded cells. Biocytin was omitted from the solution used to fill the pipette tip, because it was found to interfere with seal formation. Data were filtered at $10 \mathrm{kHz}$ and sampled at $10-20$ $\mathrm{kHz}$ using an ITC-16 data acquisition board (Instrutech, New York, NY) connected to a Macintosh computer. Current commands and data acquisition were controlled by custom macros written in Igor Pro (WaveMetrics, Lake Oswego, OR) and external operations written in the C programming language (kindly provided by Dr. Fred Rieke, University of Washington, Seattle, WA). Voltage data were corrected for a measured liquid junction potential of $-5 \mathrm{mV}$.
Current stimuli. The membrane resistance and time constant of each cell were measured using a $50 \mathrm{pA}, 1 \mathrm{~s}$ hyperpolarizing step repeated 10 times. For $f-I$ relationships, current steps (3-4 s) were applied with and without noise. Simple Gaussian current noise was used in preference to more realistic noise sources such as trains of simulated excitatory and inhibitory conductances (Chance et al., 2002). We hoped that the simpler parameter space (mean current, SD; correlation time constant fixed at 3 $\mathrm{ms}$ ) would allow simple, easily normalized experiments to compare different neurons and obtain general insights about the effects of noise. The noise was created by convolving Gaussian white noise (independent pseudorandom points chosen from a Gaussian distribution at the experimental sampling rate) with a decaying exponential filter, $A \exp (-t / \tau)$, where $\tau=3 \mathrm{~ms}$. The current SD $\left(\sigma_{I}\right)$ was adjusted to give membrane potential fluctuations with a desired $\mathrm{SD}\left(\sigma_{v}\right)$ based on the response to a test epoch of 3-5 s duration (usually $0.1 \mathrm{nA} \mathrm{SD}$ ) with zero DC offset. The scaled noise was added to the DC steps. One unit of noise $(\sigma=1)$ was defined as the $\sigma_{I}$ required to give $\sigma_{v}=1 \mathrm{mV}$. In most experiments, noise levels $(\sigma)$ of 0 and 4 were applied. In some experiments, we used multiple noise levels $(\sigma=0,2,4$, and 6$)$. Increasing current steps were applied, alternating between noise levels, until steady-state firing decreased or failed because of depolarization block. The recovery period between stimuli was at least $11 \mathrm{~s}$.

Confirmation of cell layer and type. In a subset of experiments, biocytin was included in the recording pipette solution to confirm the cortical layer and cell type. After recording from one cell, the slice was fixed overnight in $4 \%$ paraformaldehyde and the cell was visualized using the Vectastain ABC Elite kit (Vector Laboratories, Burlingame, CA), followed by development with diaminobenzidine and $\mathrm{H}_{2} \mathrm{O}_{2}$ (Sigma Fast kit; Sigma, St. Louis, MO). All cells examined were found to be located in the intended layer, and most pyramidal neurons had apical dendrites extending into layer 1.

Analysis. Data were analyzed using custom macros written in Igor Pro. The membrane resistance $\left(R_{\mathrm{m}}\right)$ of each cell was measured from the voltage change at $900-1000 \mathrm{~ms}$ during a $50 \mathrm{pA}$ hyperpolarizing step. The membrane time constant $\left(\tau_{\mathrm{m}}\right)$ was estimated by fitting a single exponential, $V_{\mathrm{m}}=V_{0}+A \exp \left(-\mathrm{t} / \tau_{\mathrm{m}}\right)$, to the initial, monotonic portion of the membrane potential $\left(V_{\mathrm{m}}\right)$ deflection ( 0 to $\left.20-50 \mathrm{~ms}\right)$. Spikes were detected off-line using an amplitude threshold adjusted for each cell to find the smallest spikes without contamination by subthreshold membrane potential fluctuations. In most cells, a threshold of $0 \mathrm{mV}$ was used. In a few cells, this was lowered to -10 or $-20 \mathrm{mV}$ to detect spikes that occurred during near-maximal stimuli that caused spike amplitude to decrease. In all cases, spikes were clearly distinguishable from subthreshold voltage fluctuations. Putative spikes with higher points within $1 \mathrm{~ms}$ on either side were rejected to avoid any double counting during highnoise stimulation. The instantaneous firing rate was calculated as the inverse of the current interspike interval at each time point. $f-I$ relationships for a given time interval were plotted based on the average instantaneous firing rate across the interval during each step.

For pyramidal neurons, the effect of noise was decomposed into additive and multiplicative/divisive components by fitting the $f-I$ relationship obtained at a given noise level $(\sigma)$, from the first point above the current threshold to the last point before the maximal firing rate without noise, with a copy of the control (noiseless) $f-I$ relationship $\left[f_{0}(I)\right]$ that was shifted vertically along the firing rate axis and multiplied by a gain factor (see Fig. $2 A): f_{\sigma}(I)=A+(1+\Delta G) \times f_{0}(I)$.

In FS interneurons, the effect of noise was not described well by additive and multiplicative/divisive operations, and the $f-I$ relationships without noise were discontinuous (having infinite gain) at the current threshold. The $f-I$ relationships obtained in the presence of noise were fitted with the product of a line and a sigmoid function, $f=\left(k_{0}+k_{1} I\right) /[$ $\left.1+\exp \left(-\left(I-k_{2}\right) / k_{3}\right)\right]$, and the maximal gain was measured from the fit lines.

Data reported are mean \pm SEM, except as indicated. Statistical significance was evaluated using two-tailed Student's $t$ tests. For correlation analysis, $t$ values were calculated based on Pearson's correlation coefficient $(r)$ and the number of pairs of observations $(n): t=r(n-2)^{1 / 2} /$ $\left(1-r^{2}\right)^{1 / 2}$, with $n-2$ degrees of freedom. Differences were considered significant when $p<0.05$. 
Table 1. Passive properties of neurons in which the effects of noise on $f-I$ relationships were measured

\begin{tabular}{llrllr}
\hline Cell type & Electrodes & $n$ & $V_{\text {rest }}(\mathrm{mV})$ & $R_{\mathrm{m}}(\mathrm{M} \Omega)$ & $\tau_{\mathrm{m}}(\mathrm{ms})$ \\
\hline Layer 2/3 pyramidal & Patch & 13 & $-81 \pm 4$ & $55 \pm 19$ & $14.1 \pm 3.7$ \\
Layer 2/3 regular spiking & Sharp & 8 & $-70 \pm 11$ & $42 \pm 17$ & $11.4 \pm 4.1$ \\
Layer 5 pyramidal & Patch & 29 & $-73 \pm 6$ & $40 \pm 16$ & $14.3 \pm 4.1$ \\
Layer 5 FS & Patch & 8 & $-78 \pm 5$ & $78 \pm 12$ & $5.5 \pm 1.3$ \\
\hline
\end{tabular}

Values are mean $\pm S D$

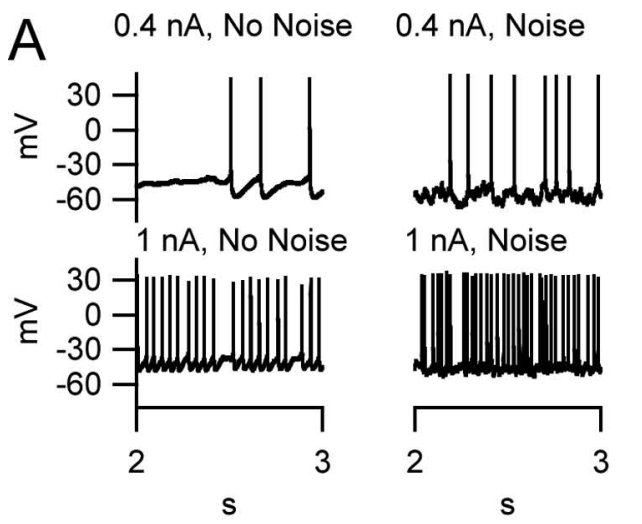

\section{B Layer 2/3 Pyramidal Neuron}
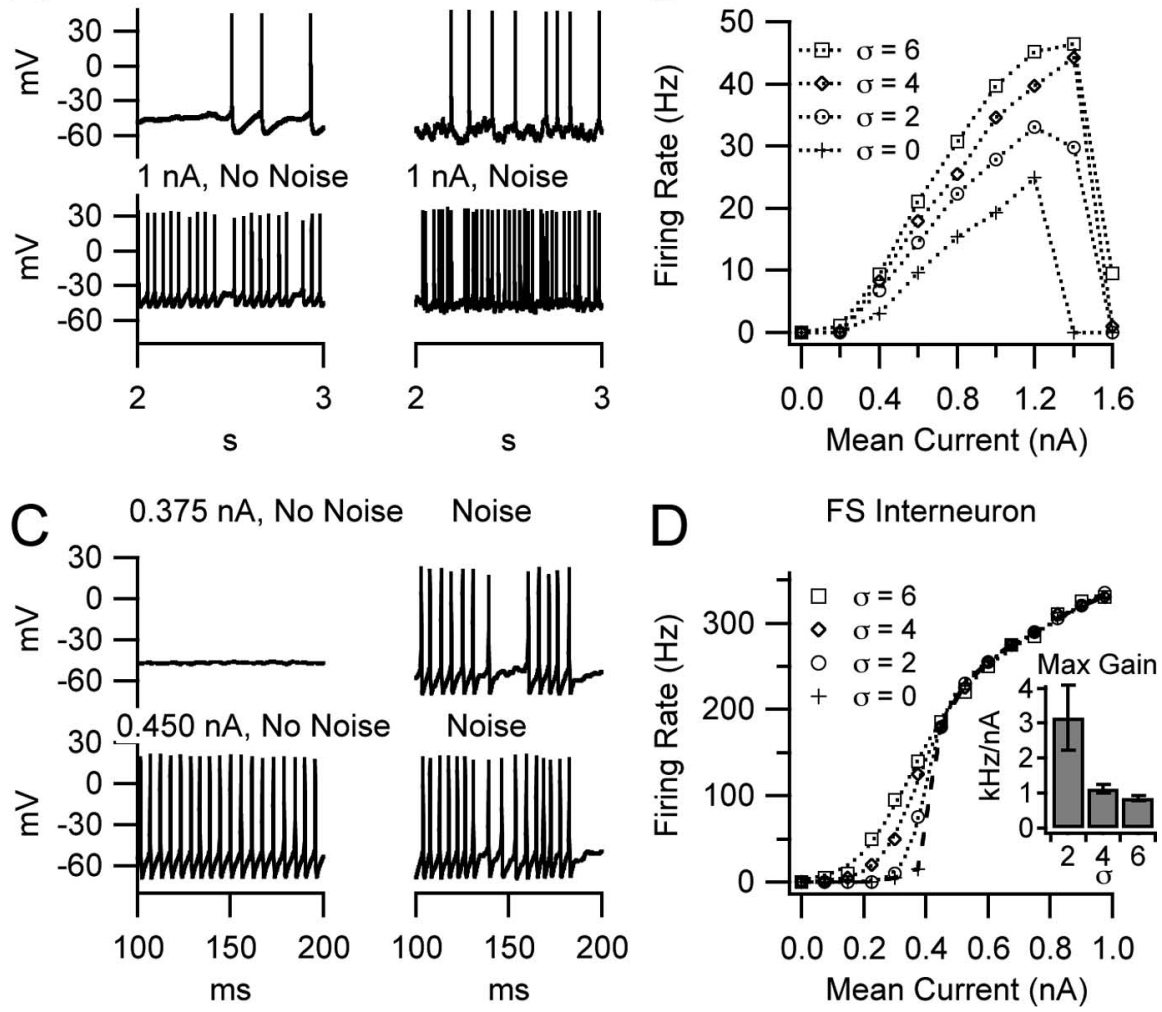

Figure 1. Noise had different effects on $f-/$ relationships in layer $2 / 3$ pyramidal neurons and FS interneurons. $\boldsymbol{A}$, Voltage traces showing steady-state firing in a layer $2 / 3$ pyramidal cell at mean currents of $0.4 \mathrm{nA}$ (top) and $1.0 \mathrm{nA}$ (bottom), without noise (left) and with noise ( $\sigma=4$; right). Noise clearly increased the firing rate at both current levels. $\boldsymbol{B}, f-I$ relationships of the same pyramidal neuron at multiple noise levels $(\sigma=0,2,4$, and 6$)$, showing that gain increased progressively with higher noise. $\boldsymbol{C}$, Voltage traces showing firing in a layer $5 \mathrm{FS}$ interneuron at a mean current slightly below threshold (top) and a current slightly above threshold (bottom), without noise (left) and with noise ( $\sigma=4$; right). Noise caused rapid firing at the just-subthreshold current but had little effect on the firing rate with suprathreshold current. $D, f-/$ relationships of the same FS interneuron at multiple noise levels $(\sigma=0,2,4$, and 6$)$, showing an abrupt rate increase at threshold without noise and progressive gain reduction by noise. Inset, Average maximal (Max) gain in FS interneurons $(n=8)$ at three noise levels.

Materials. All chemicals were obtained from Sigma, except when stated otherwise.

\section{Results}

Whole-cell, somatic current-clamp recordings were obtained from neurons in slices of rat sensorimotor cortex, including 73 pyramidal cells in layer 5, 45 pyramidal cells in layer $2 / 3$, and eight FS interneurons in layer 5. Large somas, prominent apical dendrites, and regular spiking patterns identified pyramidal neurons. No repetitively bursting cells were encountered in this study. FS interneurons were identified by smaller, rounder somata, multipolar dendrites, thin spikes with prominent fast AHPs, and the ability to sustain a firing rate $>200 \mathrm{~Hz}$ for at least $200 \mathrm{~ms}$ after onset of a noiseless current step. In some experiments, the cortical layer and cell type were confirmed by biocytin histochemistry. In addition, we recorded from eight regular-spiking neurons in layer $2 / 3$ using sharp microelectrodes filled with $3 \mathrm{~m} \mathrm{KCl}$. Firing $f-I$ relationships were obtained using current steps of 3-4 s duration with and without exponentialfiltered Gaussian noise ( $\tau=3 \mathrm{~ms})$. The noise amplitude was chosen to produce membrane potential fluctuations with a $\mathrm{SD}$ of $4 \mathrm{mV}$ when applied with no DC offset, except as indicated. We refer to this level of noise as " $\sigma=4$." Cells that were unable to fire continuously during noiseless current steps, or fired only irregularly at low rates $(<10 \mathrm{~Hz})$, were excluded from analysis. All cells had action potentials that overshot $0 \mathrm{mV}$. The resting membrane potential, input resistance, and membrane time constant of those cells used for the primary noise stimulation experiments are listed in Table 1.

\section{Noise had different effects in pyramidal neurons and FS interneurons}

In pyramidal neurons, noise increased firing rates across a wide range of suprathreshold currents. Figure $1 A$ shows the firing of a layer $2 / 3$ pyramidal neuron $2-3 \mathrm{~s}$ after onset of 0.4 and $1.0 \mathrm{nA}$ current stimuli with and without noise. During this time window, noise increased the number of spikes fired at both current levels, from 3 to 8 at $0.4 \mathrm{nA}$ and from 20 to 34 at $1.0 \mathrm{nA}$. Interestingly, the absolute increase in firing rate caused by noise was greater at the higher current $(14 \mathrm{~Hz})$ than at the lower current $(5 \mathrm{~Hz})$. Conversely, it may be seen that increasing the current from 0.4 to 1.0 $\mathrm{nA}$ produced a larger rate increase with noise $(26 \mathrm{~Hz})$ than without noise $(17 \mathrm{~Hz})$. In other words, noise increased gain between these current levels. We plotted $f-I$ relationships at multiple noise levels based on the mean firing rates from 2 to $3 \mathrm{~s}$ after stimulus onset (Fig. $1 B$ ). Because we generally observed little change in rate during this period, we refer to it as "steady state." This description is approximate, because we did not select data for analysis based on whether a criterion for constant rate was met. As seen from the individual responses described above, the increase in rate caused by noise was greater at high mean currents than near threshold. Thus, noise increased the gain of the $f-I$ relationship.

Typical effects of noise in an FS interneuron are shown in Figure $1 C$. At a mean current slightly below threshold (top panels), noise triggered rapid firing. Just above threshold (bottom panels), fast spiking to noiseless current began abruptly. This sudden increase in firing rate at threshold, known as type II firing, has been described previously in FS interneurons (Erisir et al., 1999; Tateno et al., 2004). Above threshold noise had little effect on the average rate, although it still caused some irregularity of interspike intervals. The $f-I$ relationships of this cell at multiple noise levels are shown in Figure $1 \mathrm{D}$. Immediately above threshold, the firing rate without noise jumped to almost $200 \mathrm{~Hz}$. The 
rate then increased gradually with greater current. Noise caused firing below threshold but lost effect at higher currents where the $f-I$ relationships at all noise levels rapidly converged. Because the discontinuity of the type II $f-I$ relationship provides infinite gain at threshold for noiseless stimuli, noise can only reduce gain across the wide range of firing rates spanned by the jump. In all of the FS interneurons tested, we observed a progressive reduction in maximal gain across the range of noise levels tested (Fig. $1 D$, inset). The data shown were obtained during the first $200 \mathrm{~ms}$ after stimulus onset. In some FS interneurons, firing continued with little change in rate during stimuli of $3 \mathrm{~s}$ duration. In others, firing failed abruptly or broke into long, intermittent bursts. However, in cells that fired continuously for $3 \mathrm{~s}$, similar effects were observed during the last second of each step (data not shown). These results indicate that the effects of noise on the firing rate are qualitatively different in pyramidal neurons and FS interneurons. The effects seen in FS interneurons were relatively predictable; noise smoothed the discontinuity of the type II $f-I$ relationship, causing fast spiking at subthreshold currents and reducing gain. The gain increases caused by noise in pyramidal neurons were unexpected and were investigated by the studies described below.

\section{Additive and multiplicative effects of noise in pyramidal neurons}

We decomposed the effects of noise on the mean firing rate of pyramidal neurons into additive and multiplicative/divisive components by fitting the $f-I$ relationship obtained in the presence of noise with a vertically shifted, scaled copy of the $f-I$ relationship without noise, $f_{\sigma}(I)=A+(1+\Delta G) f_{0}(I)$, giving an additive rate increase by noise $(A)$ and a gain change $(\Delta G)$ (Fig. $2 A)$. In the example shown, $A=3.0 \mathrm{~Hz}$ and $\Delta G=0.57$. In other words, noise increased the firing rate by $3.0 \mathrm{~Hz}$ at a current near threshold (defined based on the $f-I$ relationship without noise) and increased gain by $57 \%$.

Noise $(\sigma=4)$ increased steady-state gain in 37 of 43 pyramidal neurons, including 25 of 29 layer 5 cells recorded with wholecell patch electrodes, 6 of 6 layer $2 / 3$ cells recorded with patch electrodes, and 7 of 8 regular-spiking layer $2 / 3$ neurons recorded with sharp microelectrodes. On average, $A$ did not differ significantly between layer 5 and layer $2 / 3$ cells (Fig. $2 B$ ), whereas gain increase $(\Delta G)$ was larger in layer $2 / 3$ cells than in layer 5 cells (Fig. $2 C)$.

The effects of noise were graded with noise amplitude. In a subset of pyramidal neurons (seven in layer 5 and five in layer $2 / 3)$, we obtained $f-I$ relationships at multiple noise levels $(\sigma=0$, 2,4 , and 6). These values were chosen to span a physiological range, based on reports that the SD of the subthreshold membrane potential $\left(\sigma_{v}\right)$ observed in cortical pyramidal cells during active "up states" is $\sim 2-4 \mathrm{mV}$ (Destexhe and Paré, 1999; Shu et al., 2003). The $A$ and the $\Delta G$ both increased monotonically with noise amplitude (Fig. $2 D, E$ ).

The effects of noise also varied with stimulus duration. Using the same data obtained with 3-4 s current steps with and without noise $(\sigma=4)$, we measured the $f-I$ relationships for the first 100 $\mathrm{ms}, 300 \mathrm{~ms}, 1 \mathrm{~s}$, and $3 \mathrm{~s}$ of stimulation. A decreased with longer stimulus duration (Fig. $2 F$ ), whereas $\Delta G$ increased (Fig. $2 G$ ). On average, noise caused little change in gain during the first $100 \mathrm{~ms}$ but increased gain during longer periods. Interestingly, prominent slow $(>1 \mathrm{~s}$ ) changes in $A$ and $\Delta G$ were observed in layer $2 / 3$ cells but were less common in layer 5 cells, suggesting that slow adaptive mechanisms that are more common in layer $2 / 3$ may promote gain increases caused by noise.

In pyramidal neurons in which noise increased gain, firing rates at low and high noise levels did not converge at the upper end of the $f-I$ relationship. Rather, noise continued to increase the firing rate even at the highest current that could be applied without causing spike failure. Thus, noise increased the maximal steady-state firing rate in both layer $2 / 3$ and layer 5 pyramidal neurons (Fig. $2 H$ ). Interestingly, the gain increase by noise $(\Delta G)$ was correlated with the increase in maximal rate $(r=0.59 ; p=$ 0.00003 ) (Fig. 2I). These data suggest that noise limits the effect of a mechanism that controls gain and also contributes to spike failure.

\section{Gain changes in pyramidal neurons were correlated with the sAHP}

The slow decrease in $A$ and the increase in $\Delta G$ observed in many pyramidal neurons indicate that slow adaptation alters the effects of noise. Slow spike-frequency adaptation in these cells results in large part from spike-triggered $\mathrm{Ca}^{2+}$ - and $\mathrm{Na}^{+}$-dependent $\mathrm{K}^{+}$ conductances that cause a sAHP after repetitive spiking (Madison and Nicoll, 1984; Schwindt et al., 1988, 1989). We found that slow adaptation and the sAHP were prominent in most layer $2 / 3$ cells (Fig. 3A) and some layer 5 cells (Fig. 3C) but small in other layer 5 cells (Fig. 3B), consistent with previous studies (Mason and Larkman, 1990; Gottlieb and Keller, 1997; Schwindt et al., 1997; Franceschetti et al., 1998; Akemann et al., 2004). Adaptation caused by the sAHP conductance is known to reduce gain (Spain, 1994; Benda and Herz, 2003), and slow adaptation in neocortical pyramidal neurons has been observed to be reduced during noisy stimuli (Tang et al., 1997). Together, these observations suggest that the sAHP may selectively reduce gain during low-noise stimuli, allowing noise to increase gain at steady state.

As a first test of this hypothesis, we measured the correlations between sAHP amplitude, $A$, and $\Delta G$ in the 43 pyramidal neurons described above. Exactly 30 spikes at $50 \mathrm{~Hz}$ using $2 \mathrm{~ms}$ current pulses of sufficient amplitude to trigger one spike on each pulse elicited the sAHP. Positive holding current was applied to set the membrane potential to approximately $-65 \mathrm{mV}$ before the pulse train, and the sAHP amplitude was taken as the mean $V_{\mathrm{m}}$ from 450 to $550 \mathrm{~ms}$ after the train, relative to the pretrain baseline. The distribution of sAHP amplitudes in layer 5 pyramidal neurons ( $n=73$, including 30 cells not tested with noise stimuli) was broad and appeared bimodal, whereas that of layer $2 / 3$ cells $(n=38)$ appeared unimodal, corresponding roughly to the peak of larger sAHPs in layer 5 (Fig. 3D). In 43 pyramidal neurons, $A$ showed a small negative correlation with sAHP amplitude that was not significant $(r=-0.27 ; p=0.08)$ (Fig. $3 E)$, whereas $\Delta G$ had a positive correlation $(r=0.48 ; p=0.001)$ (Fig. $3 F)$. These data indicate that variation of sAHP amplitude can account for a fraction of the variance in gain change caused by noise $\left(r^{2}=\right.$ 0.23 ). Additional studies were required to determine whether the sAHP conductance actually causes noise to increase gain or is simply found on pyramidal neurons that have other mechanisms with this effect.

\section{The 5- $\mathrm{HT}_{2}$ agonist $\alpha$-methyl-5-HT eliminated gain increases caused by noise}

To further test the hypothesis that the sAHP conductance positively modulates the gain change caused by noise, we manipulated the sAHP in layer $2 / 3$ pyramidal neurons by perfusing slices with the 5- $\mathrm{HT}_{2}$ agonist $\alpha$-methyl-5-HT ( $\alpha$ me5HT) $(10 \mu \mathrm{M})$. This compound was previously shown to reduce the SAHP (Villalobos et al., 2005) and increase gain (Zhang and Arsenault, 2005), actions shared with several neuromodulators including serotonin, acetylcholine, and norepinephrine (Schwindt et al., 1988, 1989; 

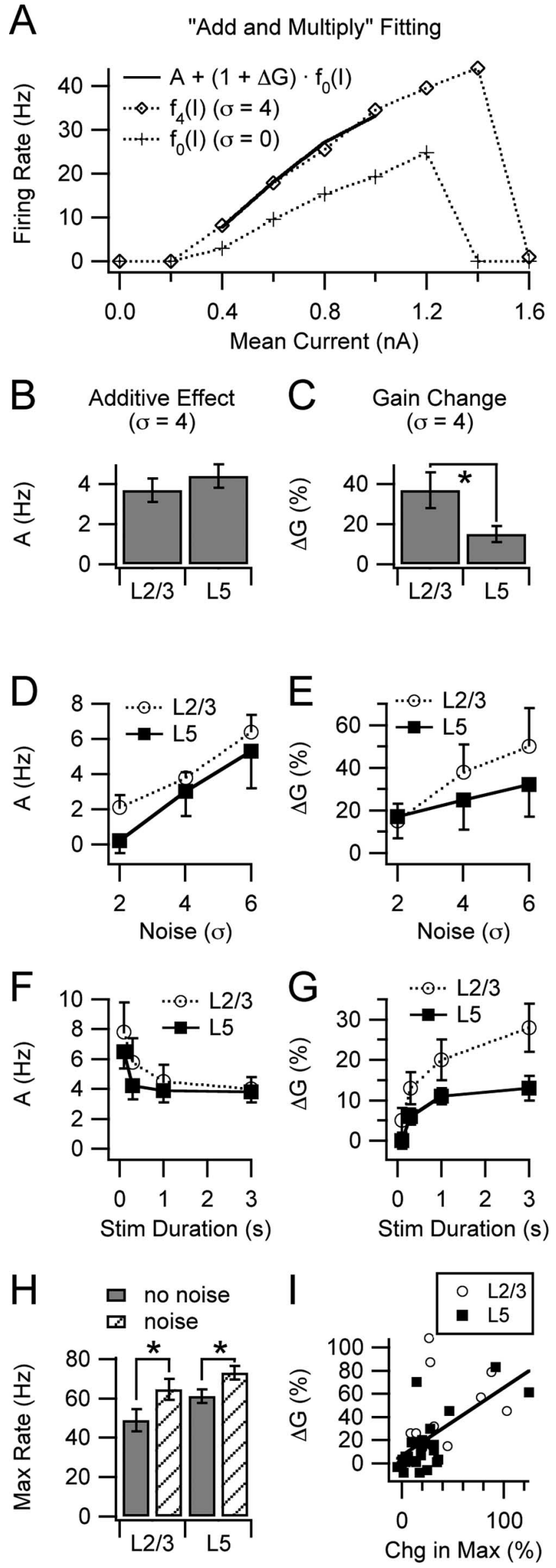

Foehring et al., 1989; Lorenzon and Foehring, 1993; Cox et al., 1994; Spain, 1994). To prevent any effects attributable to altered synaptic activity, the control recording solution for these experiments contained DNQX $(20 \mu \mathrm{M})$, CPP $(5 \mu \mathrm{M})$, and picrotoxin $(100 \mu \mathrm{M})$ to block AMPA/kainate, NMDA, and $\mathrm{GABA}_{\mathrm{A}}$ receptors, respectively. Because of concerns about the stability of whole-cell recordings during repeated $f-I$ relationships before and after drug application, these experiments were performed using a faster protocol of current ramps $(0-1 \mathrm{nA}$ in $10 \mathrm{~s}$, followed by a $20 \mathrm{~s}$ recovery period), alternating between ramps with and without noise. A fixed current $\mathrm{SD}\left(\sigma_{I}\right)$ of $0.2 \mathrm{nA}$ was used in these studies. This was similar to the mean $\sigma_{I}$ that gave $\sigma_{v}=4 \mathrm{mV}$ in the layer $2 / 3$ cells described above $(0.187 \pm 0.014 \mathrm{nA})$. Control data using ramps (see below) showed additive and multiplicative effects of noise similar to those observed in studies using steps. We analyzed the effects of $\alpha$ me5HT in six of seven layer $2 / 3$ pyramidal neurons recorded, excluding one cell with an exceptionally small control sAHP amplitude of $2.7 \mathrm{mV}$ (interestingly, noise did not increase gain in this cell even before drug application). In the six cells analyzed, $\alpha$ me5HT reduced the sAHP from $5.7 \pm 0.7$ to $1.2 \pm 0.2 \mathrm{mV}(p=0.0005)$ (Fig. $4 A$ ). Analysis of $f-I$ relationships obtained before and during drug application (Fig. $4 B, C)$ revealed that $\alpha$ me5HT increased the additive effect of noise (Fig. 4D) and eliminated the gain increase caused by noise (Fig. $4 E$ ). These results are consistent with the hypothesis that the sAHP conductance contributes to the gain increase caused by noise and also suggest that serotonin or other neuromodulators may regulate the effects of noise. However, we cannot exclude the possibility that multiple ionic mechanisms affected by $5-\mathrm{HT}_{2}$ receptors may regulate gain changes caused by noise.

\section{An artificial sAHP applied by dynamic-clamp enhanced gain} increases by noise

To manipulate the sAHP conductance in a well-defined manner without using nonselective pharmacological agents, we increased its amplitude by adding an artificial sAHP conductance $\left(G_{\text {asAHP }}\right)$ to layer 5 pyramidal neurons by a spike-triggered dynamiccurrent clamp. A schematic of the method is shown in Figure $5 \mathrm{~A}$. When a spike is detected, a pulse generator is triggered, injecting a brief ( $1 \mathrm{~ms})$ negative current pulse into a parallel resistor and capacitor (RC circuit), the voltage $\left(V_{\mathrm{RC}}\right)$ of which relaxes with a

$\leftarrow$

Figure 2. Noise had additive and multiplicative effects on $f-I$ relationships in pyramidal neurons. $A, f-I$ relationships of a layer $2 / 3$ pyramidal cell with noise $\left[f_{4}(I)\right.$, at $\left.\sigma=4\right]$ and without noise $\left[\mathrm{f}_{0}(I)\right.$, at $\left.\sigma=0\right]$, showing the fitting procedure used to measure the $A$ and the $\Delta G$. The solid line shows the fit of $f_{4}(I)$ with a copy of $f_{0}(I)$ that was multiplied by $1+\Delta G$ and shifted upward by $A . B$, Bar graph showing the mean additive effect of noise in layer $2 / 3$ neurons $(n=14)$ and layer 5 neurons $(n=29)$. The additive effect did not differ significantly between layer $2 / 3$ and layer 5 . C, Bar graph showing the mean gain increase by noise in layer $2 / 3$ and layer 5. The average gain increase was greater in layer $2 / 3$ than in layer 5 . D, Plots showing the mean additive effect versus noise amplitude in layer $2 / 3$ neurons $(n=5)$ and layer 5 neurons $(n=7)$. The additive effect increased with noise amplitude in both layers. $\boldsymbol{E}$, Mean gain change versus noise amplitude. The gain change increased with noise amplitude in both layers. $\boldsymbol{F}$, Mean additive effect of noise versus stimulus duration. The additive effect decreased with longer stimulus duration. $G$, Mean gain change versus stimulus duration. The gain increase grew with longer stimuli. $\boldsymbol{H}$, Bar graph showing the maximal steady-state firing rate attained before depolarization block occurred (taken from 2-3 s after stimulus onset) with and without noise $(\sigma=4)$ in layer 2/3 and layer 5 . Noise raised the maximal steady-state firing rate in both layers. $I$, Scatter plot showing the relationship between percent gain change caused by noise $(\sigma=4)$ and percent change in the maximal (Chg in Max) firing rate. The solid line is the regression line for all data points. A significant correlation was observed, suggesting that a common mechanism might underlie both effects of noise. Asterisks indicate significant differences $(p<0.05)$ here and in subsequent figures. L2/3, Layer 2/3; L5, layer 5; Stim, stimulus. 
1 s time constant (similar to the decay of the natural sAHP). The RC circuit provides the command input to an analog dynamic-clamp circuit that produces output proportional to $V_{\mathrm{RC}} \times\left(V_{\mathrm{m}}-E_{\mathrm{K}}\right)$, where $E_{\mathrm{K}}=-99 \mathrm{mV}$ with our intracellular and extracellular solutions. This is summed with the standard current command (steps with and without noise) to give the total command to the current clamp amplifier. For the experiments described below, the gain of the circuit was adjusted (at the pulse generator) such that each spike increased $G_{\text {asAHP }}$ by $\sim 2 \%$ of the resting conductance of the cell. When multiple spikes occurred, $G_{\text {asAHP }}$ summed because of its slow (1 s) decay time constant.

To verify that the circuit operated correctly, we measured the sAHP after 30 spikes at $50 \mathrm{~Hz}$. Most of the large layer 5 pyramidal neurons targeted in this study $(n=12)$ had small control sAHPs. On average, adding $G_{\text {asAHP }}$ increased the sAHP from $2.5 \pm 0.5$ to $8.0 \pm 0.7 \mathrm{mV}$, an amplitude similar to the largest ones found naturally in layer $2 / 3$ and layer 5 pyramidal cells (compare Figs. 3, 5B). The effect of $G_{\text {asAHP }}$ may be appreciated by plotting the total injected current $\left(I_{\text {total }}\right)$ recorded during a long current step, including the positive step command $\left(I_{\text {step }}\right)$ plus the negative asAHP current ( $I_{\text {asAHP }}$ ) (Fig. 5C, bottom right). During the stimulus, $I_{\text {total }}$ relaxes downward as $G_{\text {asAHP }}$ accumulates and is sharply reduced during each spike as $V_{\mathrm{m}}$ moves further from $E_{\mathrm{K}}$. As expected, these effects are accompanied by slow spike-frequency adaptation (Fig. 5C, middle and top right). Analysis of steady-state $f-I$ relationships (Fig. 5D) showed that, as expected, $G_{\text {asAHP }}$ lowered gain. More interestingly, $G_{\text {asAHP }}$ reduced the additive effect of noise $(\sigma=4)$ (Fig. $5 E$ ) but caused noise to increase gain (Fig. $5 F$ ). In some cells, including the one illustrated, $G_{\text {asAHP }}$ also lowered the maximal steady-state firing rate. However, this effect was not significant in the sample of 12 cells tested ( $p=0.08$ without noise, $p=0.11$ with noise).

We wanted to determine whether $G_{\text {asAHP }}$ promoted gain increases by noise by acting as a simple, firing rate-dependent source of sustained hyperpolarizing current, or whether the shunting effect of $G_{\text {asAHP }}$ was critical. In the first case (mean current effect), a gain change by noise might result from interactions between DC and noise that affect mean interspike $V_{\mathrm{m}}$, altering the driving force for $\mathrm{K}^{+}$current $\left(V_{\mathrm{m}}-E_{\mathrm{K}}\right)$ and thereby changing the mean $I_{\text {asAHP. }}$ In the second case (shunting effect), $G_{\text {asAHP }}$ might cause noise to increase gain by shunting currents that shape the interspike voltage trajectory. The essential difference between the mean current effect and the shunting effect is that shunting results from voltage-dependent changes in $I_{\text {asAHP }}$ across each interspike interval.
Layer 2/3 Pyramidal Neuron
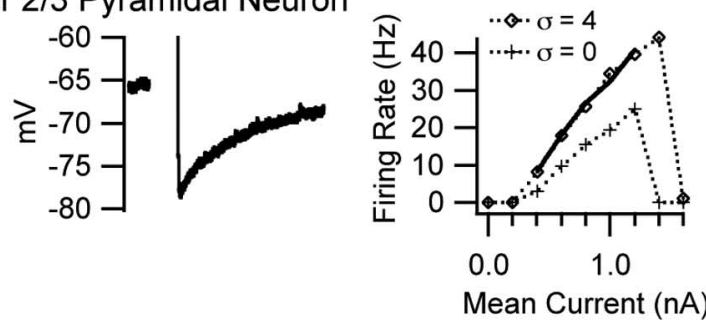

Layer 5 Pyramidal Neuron

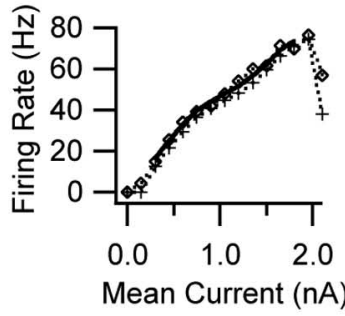

Layer 5 Pyramidal Neuron
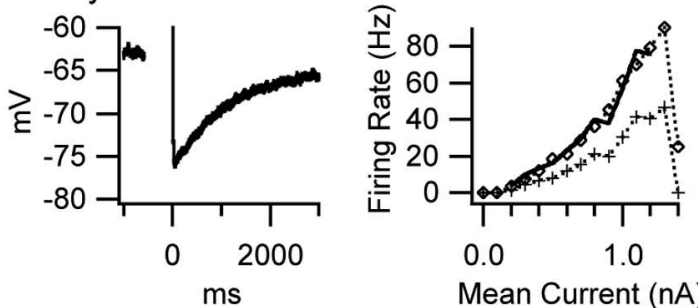

F
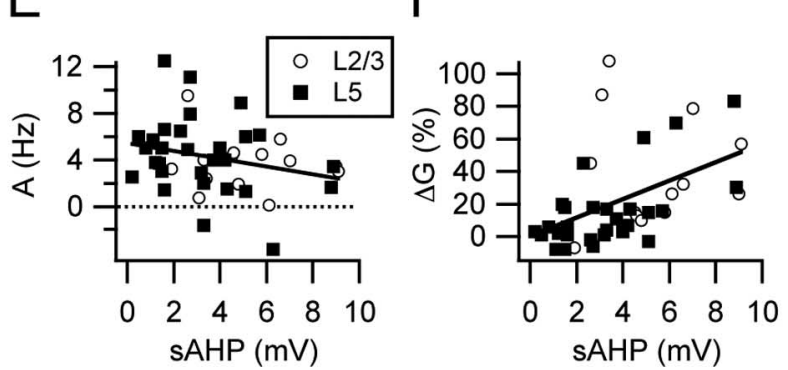

Figure 3. Diversity of spike-frequency adaptation, SAHP amplitude, and gain change by noise in pyramidal neurons. $\boldsymbol{A}-\boldsymbol{C}$, Left plots show voltage traces of firing during the first $500 \mathrm{~ms}$ of noiseless current steps, middle plots show AHPs after 30 spikes at 50 $\mathrm{Hz}$, and right plots are $f-/$ relationships with noise $(\sigma=4)$ and without noise $(\sigma=0)$. Solid lines are fits to the $f-/$ relationships gain change by noise. $C$, Another layer 5 pyramidal neuron with slow adaptation, a large SAHP, and gain increase by noise. $\boldsymbol{D}$ Distribution of sAHP amplitude in layer 2/3 pyramidal cells (top) and layer 5 pyramidal cells (bottom). $\boldsymbol{E}$, Scatter plot showing the relationship between SAHP amplitude and the additive effect of noise. The solid line is the linear regression for all data points. The small negative correlation between these measures was not significant. L2/3, Layer 2/3; L5, layer 5. F, Relationship between sAHP amplitude and gain change by noise, showing a significant positive correlation.

To determine whether the mean current effect or the shunting effect of $G_{\text {asAHP }}$ was responsible for gain changes caused by noise, we recorded the total injected current $\left(I_{\text {total }}=I_{\text {step }}+I_{\text {asAHP }}\right)$ in five layer 5 pyramidal neurons and plotted the steady-state firing rate (2-4 s after stimulus onset) against mean steady-state $I_{\text {total }}$, thereby removing the mean current effect of $G_{\text {asAHP. }}$ A representative example is shown in Figure $6 \mathrm{~A}$. For noisy stimuli, the $f-I_{\text {total }}$ relationship with $G_{\text {asAHP }}$ was similar to the control $f-I$ relationship. This indicates that the mean current effect of $G_{\text {asAHP }}$ primarily accounted for its effect on the $f-I$ relationship obtained with noise. However, in the absence of noise, the $f-I_{\text {total }}$ relationship with $G_{\text {asAHP }}$ had a lower slope than the control curve. This effect must result from shunting. 
A
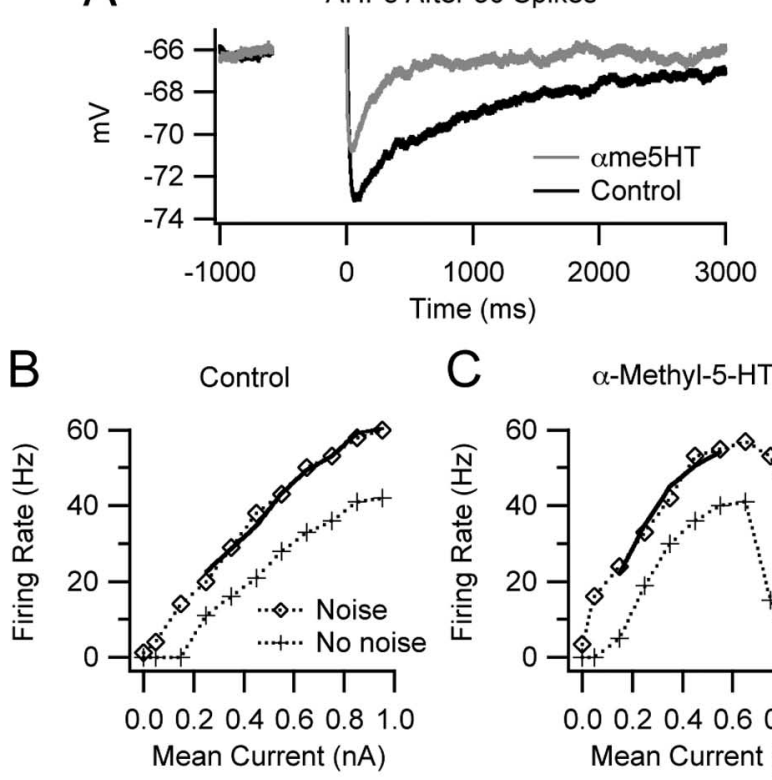

C $\quad \alpha-$ Methyl-5-HT

$\mathrm{D}$

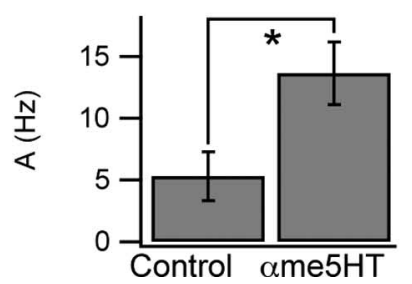

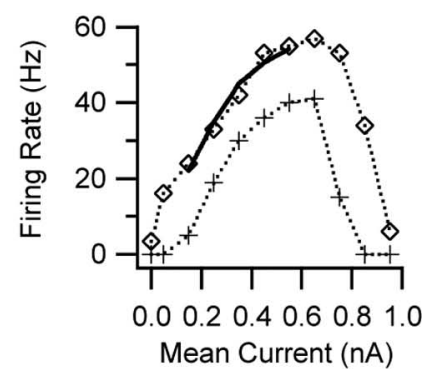

$E$

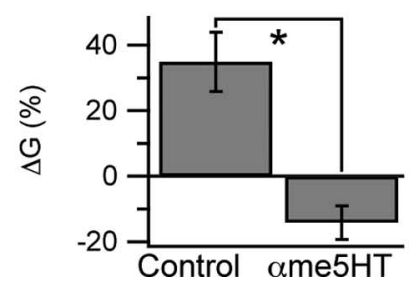

Figure 4. The 5- $\mathrm{HT}_{2}$ agonist $\alpha \mathrm{me} 5 \mathrm{HT}(10 \mu \mathrm{m})$ reduced the SAHP and eliminated gain increases caused by noise in layer $2 / 3$ pyramidal neurons. $A$, AHPs after 30 spikes at $50 \mathrm{~Hz}$ in control solution and during application of $\alpha$ me5HT. The slow component of the AHP was greatly reduced. $\boldsymbol{B}$, Typical $f-/$ relationships in control solution. The curve obtained with noise diverged from the no-noise curve, showing a gain increase. The solid line is a fit to the $f-I$ relationship with noise, as described in Figure 2. $C, f-/$ relationship of the same cell in $\alpha$ me5HT, showing a nearly constant rate difference between curves obtained with and without noise. $\boldsymbol{D}$, Bar graph showing the mean additive effect of noise in control solution and while applying $\alpha$ me5HT.E, Mean gain change by noise in control solution and in $\alpha$ me5HT.

To determine whether shunting can quantitatively account for the gain increase caused by noise while applying $G_{\text {asAHP }}$, we measured the $\Delta G$ between the $f-I_{\text {total }}$ relationship with noise and that obtained without noise, using the same fitting procedure described above (Fig. $6 B$, right bar). Remarkably, this value was similar to $\Delta G$ determined from the raw $f-I$ relationship (not corrected for the mean current effect) obtained with $G_{\text {asAHP }}$ (middle bar) and significantly different from the control data from the same cells without $G_{\text {asAHP }}$ (left bar). These data indicate that shunting was primarily responsible for the gain increase caused by noise while applying $G_{\text {asAHP. }}$.

By examining action potentials and interspike voltage trajectories obtained at steady state during pure DC stimuli at the same mean $I_{\text {total }}$ with and without $G_{\text {asAHP }}$ (Fig. 6C), we obtain some clues about the effects of shunting. $G_{\text {asAHP }}$ caused an overall compression of the voltage trajectory, affecting both the action potentials and the intervals in between. In addition, the mean interspike $V_{\mathrm{m}}$ and spike threshold were elevated. These effects increased with injected current, most likely because $G_{\text {asAHP }}$ scales with the firing rate. We analyzed the behavior of mean interspike $V_{\mathrm{m}}$ (obtained after removing action potentials) and spike threshold $(\theta)$ by plotting each against mean $I_{\text {total }}$ and obtained $\mathrm{d} V_{\mathrm{m}} /$

$\mathrm{d} I_{\text {total }}$ and $\mathrm{d} \theta / \mathrm{d} I_{\text {total }}$ by linear fitting. On average, $G_{\text {asAHP }}$ increased $\mathrm{d} V_{\mathrm{m}} / \mathrm{d} I_{\text {total }}$ from $9.2 \pm 2.0$ to $11.8 \pm 1.8 \mathrm{mV} / \mathrm{nA}(n=5 ; p=0.02)$ and raised $\mathrm{d} \theta / \mathrm{d} I_{\text {total }}$ from $8.0 \pm 2.0$ to $10.1 \pm 1.5 \mathrm{mV} / \mathrm{nA}(p=$ $0.04)$. These results indicate that shunting by $G_{\text {asAHP }}$ consistently changes the interspike voltage trajectory. Based on our data described above, this effect of shunting reduces firing to low-noise stimuli but not to strongly fluctuating input.

\section{Relationship between noise effects and individual action potentials in pyramidal neurons}

The results described above indicate that the sAHP conductance can account for some of the variation in gain change caused by noise among pyramidal cells. However, other ionic mechanisms may also regulate the gain change. Indeed, spike-frequency adaptation introduced by an AHP conductance does not cause noise to increase gain in leaky integrate-and-fire models (Rauch et al., 2003; La Camera et al., 2004), indicating that the ability of the sAHP to promote gain increases by noise must depend on interaction with other mechanisms. In neocortical pyramidal neurons, slow inactivation of voltage-gated $\mathrm{Na}^{+}$channels contributes to spike-frequency adaptation and limits the maximal steady-state firing rate during strong stimuli (Fleidervish et al., 1996). Because of its shunting effect, the sAHP conductance may increase the $\mathrm{Na}^{+}$conductance required to initiate a spike, enhancing the effect of $\mathrm{Na}^{+}$inactivation and limiting the maximal firing rate. These effects may be reduced by noise, which causes rapid membrane potential fluctuations that remove fast $\mathrm{Na}^{+}$inactivation and trigger spikes. Based on this reasoning, we hypothesized that neurons that have lower initial $\mathrm{Na}^{+}$conductance, or more inactivation, may show a greater tendency for noise to increase gain.

Because intact cortical pyramidal neurons are not well suited for voltage-clamp studies to directly measure the sodium conductance, we found the maximal rate of rise of single action potentials as the best available surrogate (Madeja, 2000). As an index of the initial $\mathrm{Na}^{+}$conductance, we measured the first action potential during the first noiseless current step above threshold. Neither layer $2 / 3$ nor layer 5 pyramidal neurons showed a significant correlation between the gain increase caused by noise and the rate of rise. However, in layer 5 pyramidal neurons (Fig. 7A, filled squares), we found the largest gain increases by noise in a cluster of four cells with relatively slow-rising action potentials (circled).

To estimate the degree of $\mathrm{Na}^{+}$channel inactivation during repetitive spiking, we found the rate of rise of the first and 30th action potentials during a $50 \mathrm{~Hz}$ train elicited by a series of $2 \mathrm{~ms}$ current pulses (as used to measure the sAHP). The percentage of inactivation was not significantly correlated with the gain change caused by noise $(r=0.14 ; p=0.37)$. These data suggest that low initial $\mathrm{Na}^{+}$conductance, but not strong inactivation, may be associated with the ability of noise to increase gain in a subset of layer 5 pyramidal neurons. In contrast, noise can apparently cause substantial gain increases in layer $2 / 3$ cells despite a relatively large $\mathrm{Na}^{+}$conductance.

\section{Effects of partial sodium channel blockade on gain changes caused by noise}

As another test of the hypothesis that low $\mathrm{Na}^{+}$conductance can contribute to gain increases by noise, we treated layer 5 pyramidal neurons $(n=6)$ with $10 \mathrm{~nm}$ tetrodotoxin (TTX), a concentration that did not prevent repetitive firing but blocked a fraction of the $\mathrm{Na}^{+}$channels, as revealed by reduced action potential amplitude (Fig. 7B). On average, $10 \mathrm{~nm}$ TTX reduced the peak voltage dur- 
ing the first action potential elicited by a long, just-suprathreshold current step from $39 \pm 3$ to $30 \pm 2 \mathrm{mV}(p=0.002)$, and reduced the maximal rate of rise from $456 \pm 37$ to $360 \pm 28 \mathrm{~V} / \mathrm{s}(p=0.002)$. To reveal any interaction between the $\mathrm{Na}^{+}$ conductance and the sAHP conductance, we obtained $f-I$ relationships (in the absence or presence of noise) with and without $G_{\text {asAHP }}$, before and during application of $10 \mathrm{~nm}$ TTX. To prevent effects resulting from altered spontaneous synaptic input, the control extracellular solution for these experiments contained DNQX, CPP, and picrotoxin. We found that TTX constricted the dynamic range of the cells, increasing the current threshold for spiking (rheobase) and reducing the maximal current that could be applied before depolarization block occurred (Fig. 7C). On average, TTX increased the current threshold from $0.20 \pm 0.05$ to $0.41 \pm 0.09 \mathrm{nA}(p=$ $0.008)$. However, TTX did not usually alter the additive and multiplicative effects of noise, either alone or in combination with $G_{\text {asAHP }}($ Fig. $7 D, E$ ). The simplest interpretation of these results is that the amount of available $\mathrm{Na}^{+}$conductance does not have a major influence on gain changes caused by noise. However, it remains possible that variations in the spatial distribution or temporal properties of $\mathrm{Na}^{+}$conductance that were not mimicked by global TTX application may influence the effects of noise.

\section{Gain increase by noise in a specialized coincidence detector}

Our results suggest that pyramidal neurons with large sAHPs can function as coincidence detectors at suprathreshold currents, increasing their absolute noise sensitivity up to currents that elicit maximal steady-state firing rates. To explore the generality of this result for neuronal coincidence detectors, we obtained $f-I$ relationships for noisy current steps in neurons from chick nucleus laminaris (NL), which encode sound source location as the firing rate by detecting coincident signals from ipsilateral and contralateral afferents (Jeffress, 1948; Carr and Konishi, 1990). Because the EPSCs that these cells receive have extremely fast kinetics (Reyes et al., 1996; Kuba et al., 2005), we used noise with a fast time constant $(\tau=0.2 \mathrm{~ms})$ rather than the slower noise applied to cortical neurons ( $\tau=3 \mathrm{~ms}$ ). The $f-I$ relationships were plotted based on the last $200 \mathrm{~ms}$ of $230 \mathrm{~ms}$ stimuli. As shown previously (Reyes et al., 1996; Kuba et al., 2005), NL cells did not fire to constant current without noise. With sufficient noise rising and falling $f-I$ relationships were obtained, and the gain and maximal firing rate increased with noise amplitude (Fig. $8 \mathrm{~A}$ ). Similar results were observed in 11 cells. These results indicate that gain increases by noise are not restricted to pyramidal neurons but are prominent in at least some other neurons, the primary function of which is to encode input timing as firing rate. arrange $f-I$ relationships in a spectrum based on the interaction between mean current and noise (Fig. 8, left panels). The same data are also shown as contour plots (Fig. 8, right panels) with
Based on the variety of noise effects that we observed, we may
B
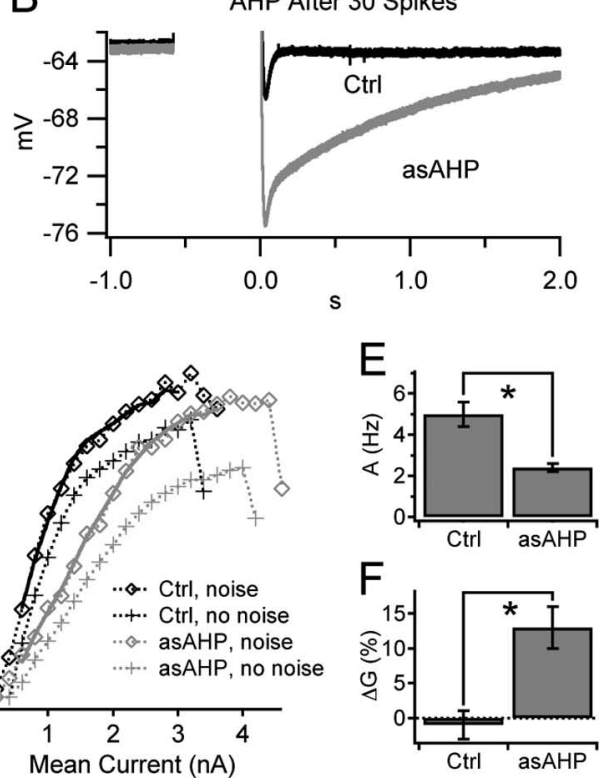

Cirl asAHP

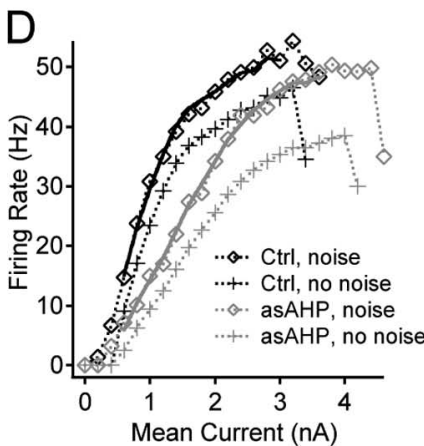

Figure 5. An artificial sAHP conductance $\left(G_{\text {asAHP }}\right)$ applied by spike-triggered dynamic-current clamp caused noise to increase 列 in Figure 2. $\boldsymbol{E}$, Bar graph showing the mean additive effect of noise in control conditions and while applying the asAHP. $\boldsymbol{F}$, Mean gain change by noise in control and with the asAHP. Ctrl, Control.

mean current on the horizontal axis, noise amplitude on the vertical axis, and firing rate indicated by isorate contours. The area occupied by brightly colored contours is the most preferred input of each cell. At one extreme, represented by the NL neuron, the interaction between mean current and noise is mutually facilitory; elevation of the firing rate by noise increases with mean current, and vice versa. At the other extreme, represented by the FS interneuron, the interaction is antagonistic (near rheobase). Neocortical pyramidal neurons with large sAHPs are relatively close to the NL end of the spectrum, whereas pyramidal cells with small sAHPs are near the middle, lacking high noise sensitivity at any level of somatic current injection. This presentation emphasizes that the effects of stimulus fluctuation on $f-I$ relationships do not follow a single, universal pattern in all neurons. Rather, a spectrum of selectivity for high net excitatory current and/or strong fluctuation exists among neurons in the neocortex and elsewhere.

Viewing these results from the standpoint of differentiation versus temporal integration, the firing rate of an ideal differentiator (with rectified output) might be completely insensitive to slow changes in the mean input current and selectively encode variance (Fig. $8 E$ ), whereas a perfect temporal integrator would show the opposite pattern (Fig. $8 F$ ). The NL cell comes closest to the ideal differentiator. The pyramidal cell with a large sAHP transitions from integration to differentiation as firing rate increases, whereas the FS interneuron transitions from differentiation to integration and the pyramidal cell with a small sAHP performs closest to an ideal temporal integrator. 


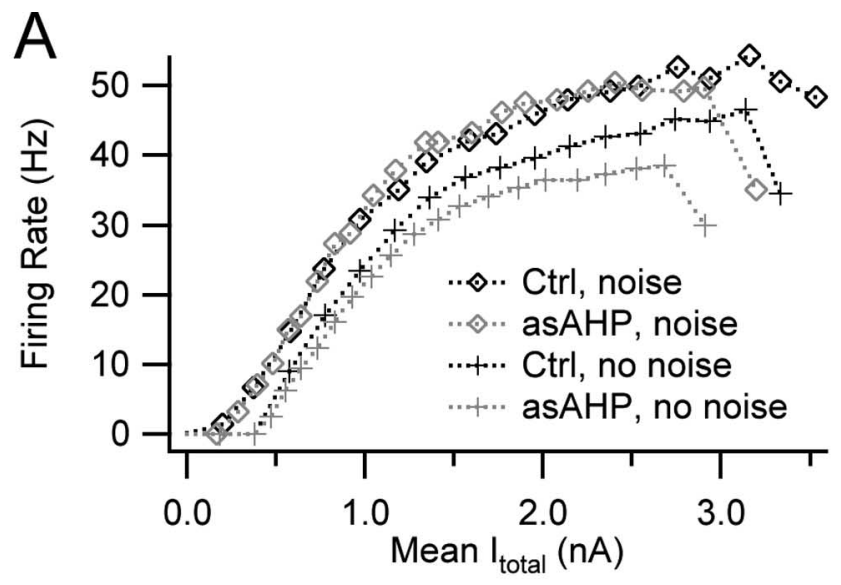

B
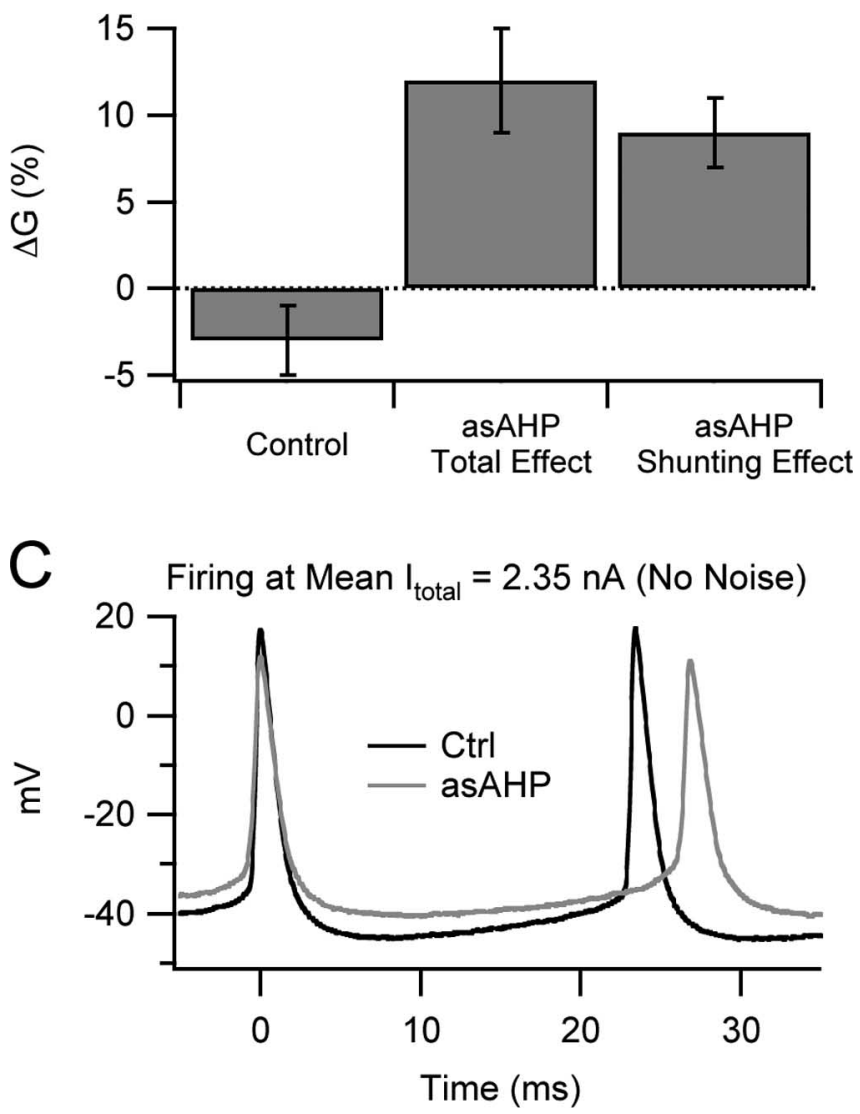

Figure 6. Shunting, rather than a change in mean total injected current, was responsible for the ability of $G_{\text {asAHP }}$ to promote gain increases by noise in layer 5 pyramidal neurons. $A$, Mean firing rate versus mean $I_{\text {total }}\left(I_{\text {step }}+I_{\text {asAHP }}\right)$ at steady state. With noise, the curves obtained with and without $G_{\text {asAHP }}$ (asAHP) nearly superimpose, indicating that the change in mean $I_{\text {asAHP }}$ caused by $G$ asAHP could account for the effects on firing rate. Without noise, the curve obtained with the asAHP had a lower slope and maximum than the control curve, indicating that shunting further reduced gain and maximal rate. $\boldsymbol{B}$, Bar graph showing the mean gain change by noise in control conditions (left), the standard gain change measurement with the asAHP (Total Effect; middle), and the gain change measured from $f-I_{\text {total }}$ relationships with the asAHP (Shunting Effect; right). This latter measure separates the shunting effect of $G_{\text {asAHP }}$ from any effect caused by changes in mean $I_{\text {total }}$. $C$, Voltage traces showing action potentials and interspike trajectories during injection of identical $I_{\text {total }}(2.35 \mathrm{nA})$ in control conditions and with the asAHP, both without noise. Shunting by $G_{\text {asAHP }}$ reduced the voltage excursions during the spikes and the interspike trajectory and increased spike threshold and mean interspike $V_{m}$. These changes were associated with longer interspike intervals (lower firing rate) during noiseless stimuli. Ctrl, Control.
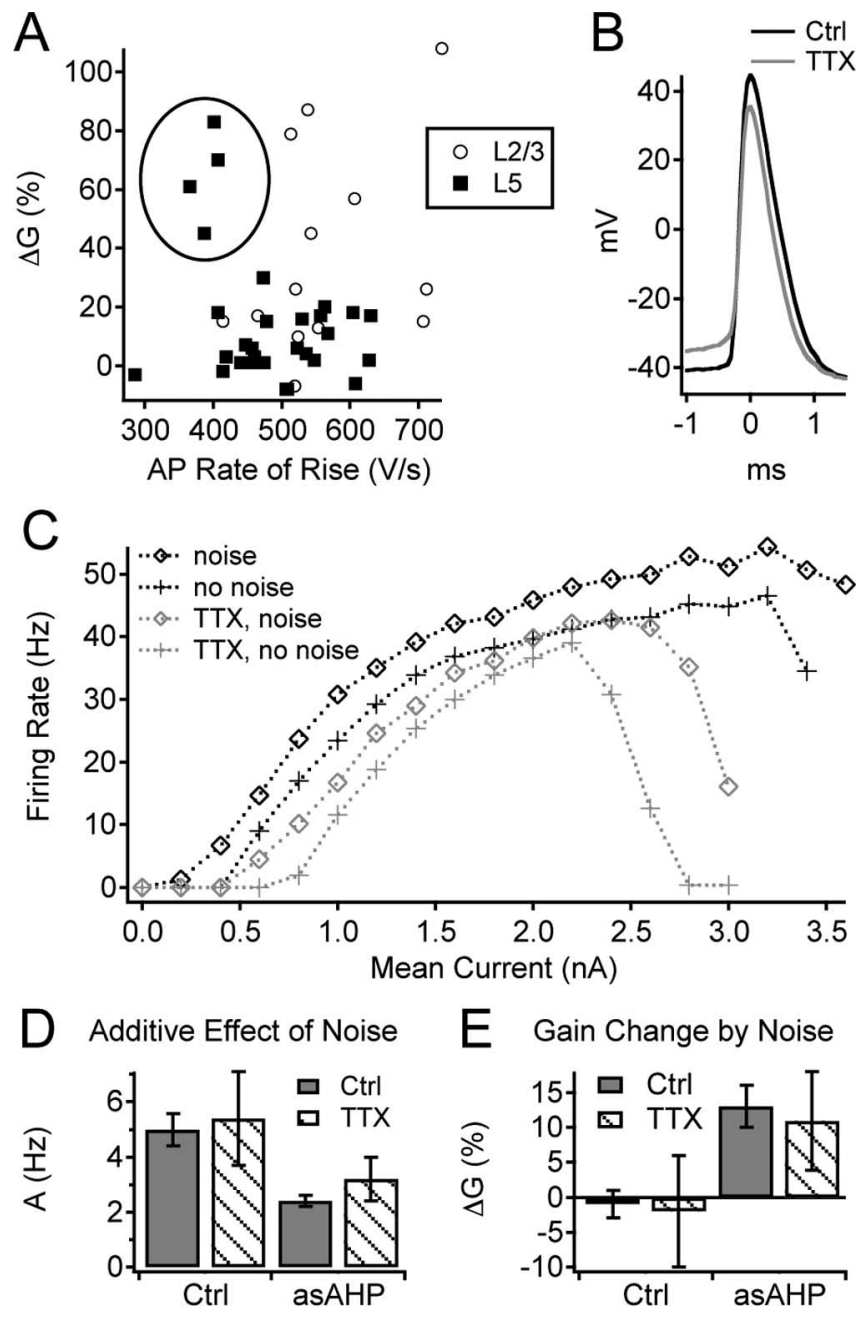

Figure 7. Relationship between available $\mathrm{Na}^{+}$conductance and the effects of noise in pyramidal neurons. $\boldsymbol{A}$, Scatter plot showing gain change by noise versus maximal rate of rise of the first action potential (AP) during a just-suprathreshold, noiseless current step. The four layer 5 (L5) pyramidal cells with the largest gain increases by noise (circled) had relatively slow-rising action potentials, suggesting a possible relationship between available $\mathrm{Na}^{+}$conductance and gain change. $L 2 / 3$, Layer $2 / 3$. $B$, Voltage traces showing the first action potential during a just-suprathreshold current step, in control solution and while applying a subsaturating concentration of TTX (10 nM). TTX increased spike threshold and reduced spike amplitude. $C, f-I$ relationships (in the absence or presence of noise) in control solution and with TTX. Application of TTX raised the current threshold and lowered the current at which spike failure occurred, but it did not cause noise to increase gain. $D$, Bar graph showing the mean additive effect of noise, with and without TTX and the asAHP. TTX did not change the additive effect of noise in control conditions or while applying the asAHP. E, Mean gain change by noise, with and without TTX and asAHP. TTX did not alter the gain change by noise in control or with the asAHP. Ctrl, Control.

\section{Discussion}

We found that noise increased gain in many pyramidal neurons but reduced gain in FS interneurons. The gain increases of the pyramidal cells were associated with large SAHPs, were eliminated by a $5-\mathrm{HT}_{2}$ agonist that reduces the sAHP, and were enhanced by augmenting $G_{\mathrm{sAHP}}$ using dynamic-clamp.

\section{Comparison to previous studies}

Several studies found that noise reduced gain in pyramidal neurons (Chance et al., 2002; Rauch et al., 2003; Shu et al., 2003) (but see Fellous et al., 2003). One explanation is that noise effects differ between subtypes of cells. Layer 5 pyramidal neurons comprise two broad groups: (1) large cells with thick, highly branched apical dendrites, axons projecting subcortically, little adaptation 
A

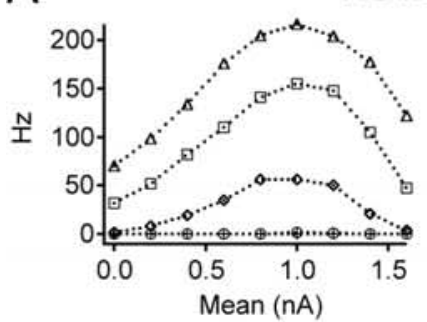

NL Neuron

B
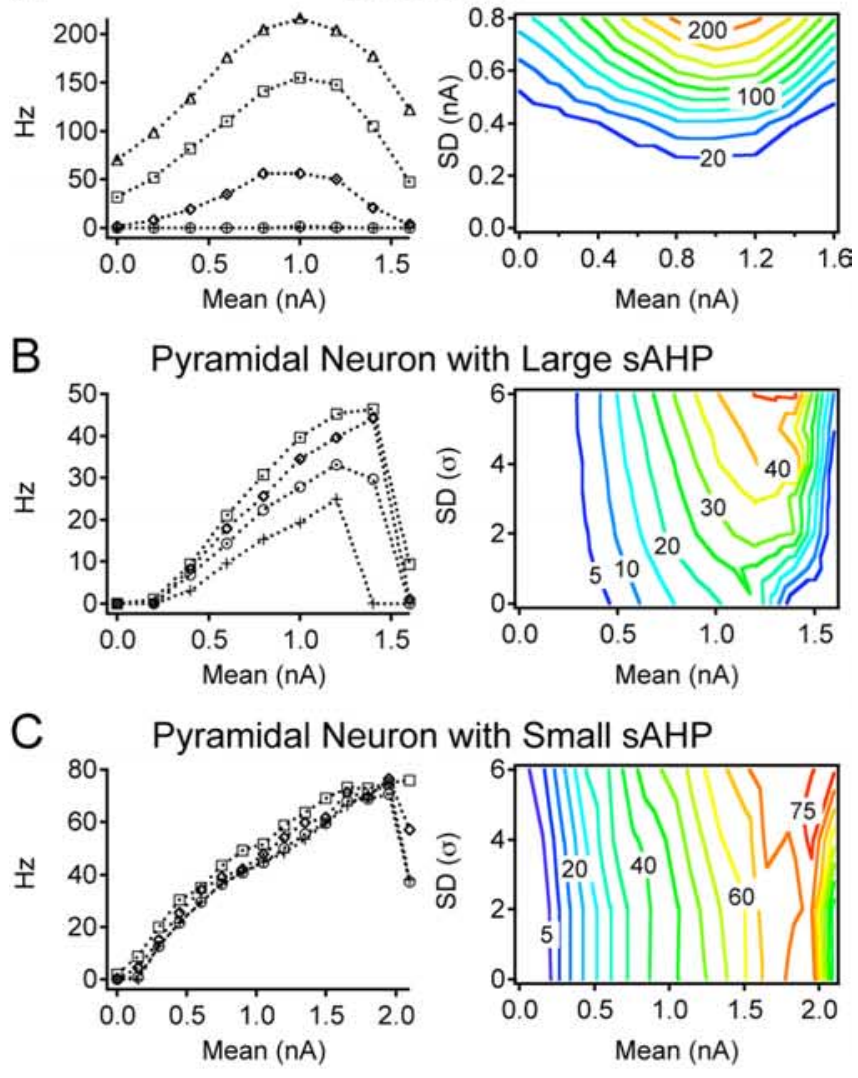

D
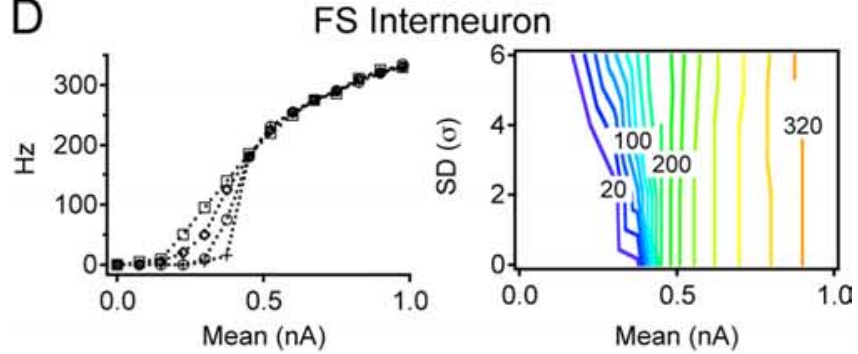

$\mathrm{E}$
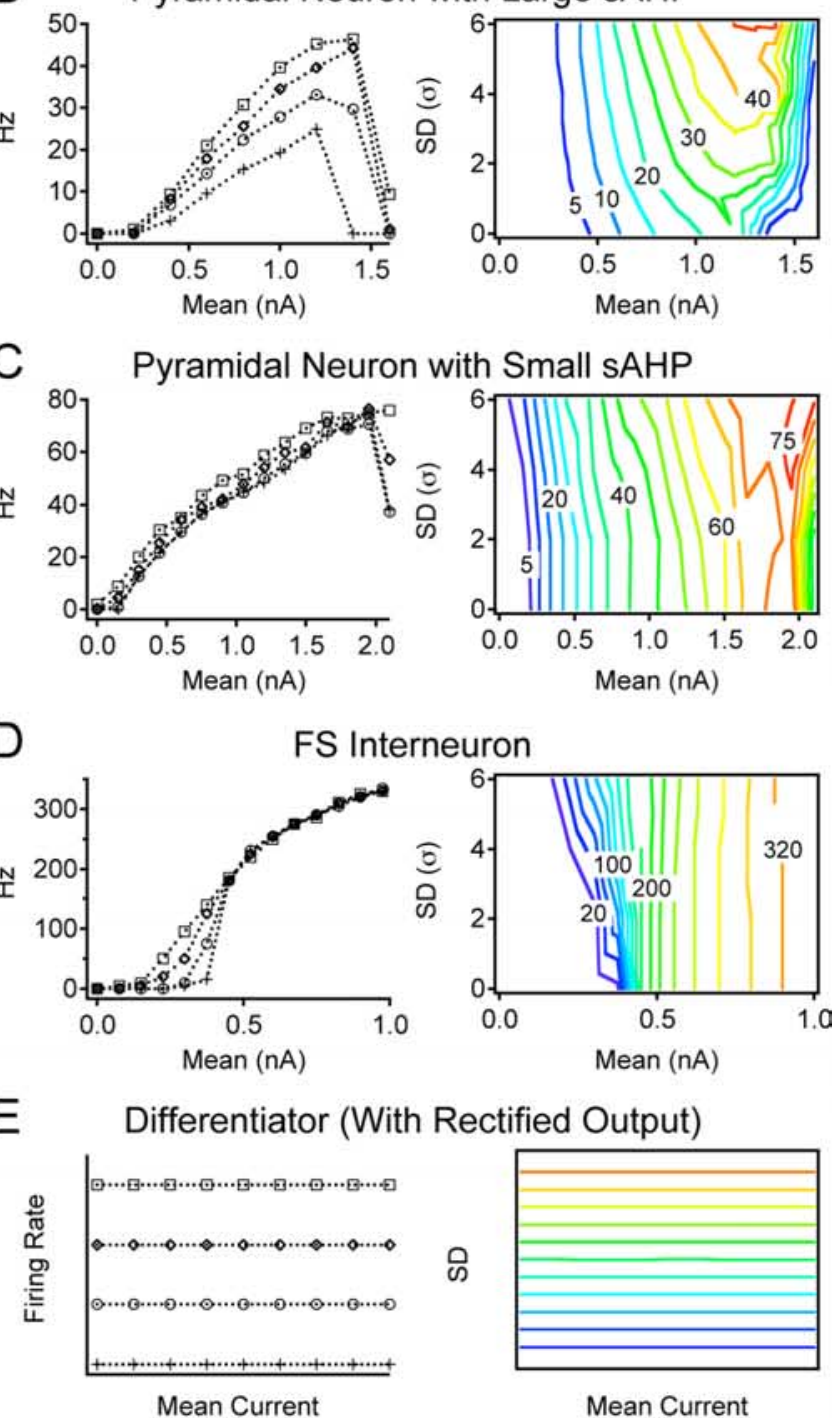

Mean Current

$\mathrm{F}$
Mean Current

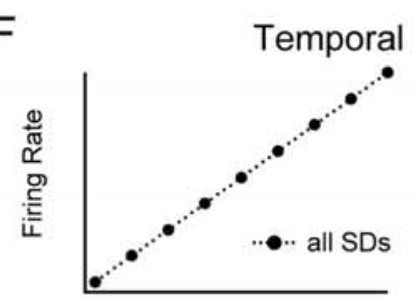

Figure 8. A wide spectrum of noise effects was observed in NL coincidence detector neurons and neocortical neurons. The left panels are $f-/$ relationships at increasing noise levels (crosses, circles, diamonds, squares, and triangles). The right panels are contour plots of the firing rate versus the mean current (horizontal axis) and noise amplitude (vertical axis). Hot colors indicate the high firing rate. Numbers are the firing rate (hertz). $A$, An NL neuron absolutely requires after an initial spike doublet or burst, and small sAHPs; and (2) smaller cells with thin, sparsely branched apical dendrites, axons projecting within the cortex, prominent slow adaptation, and large sAHPs (Larkman and Mason, 1990; Mason and Larkman, 1990; Gottlieb and Keller, 1997; Schwindt et al., 1997; Franceschetti et al., 1998; Akemann et al., 2004). Our results indicate that large gain increases occur in layer $2 / 3$ pyramidal neurons and slowly adapting layer 5 cells but not in nonadapting layer 5 cells.

Some differences may also arise from experimental methods. We and Fellous et al. (2003) used $\mathrm{KMeSO}_{4}$ intracellular solutions, which maintain the sAHP better than solutions containing other anions (Zhang et al., 1994). Chance et al. (2002) used K-gluconate, Rauch et al. (2003) used K-gluconate and high EGTA, and Shu et al. (2003) used sharp electrodes containing $\mathrm{K}$-acetate. Gain changes may also depend on the noise time constant. We used $\tau_{\text {noise }}=3 \mathrm{~ms}$, whereas Chance et al. (2002) and Shu et al. (2003) used $\tau_{\text {excitatory }}=5 \mathrm{~ms}$ and $\tau_{\text {inhibitory }}=10 \mathrm{~ms}$. In several pyramidal neurons with large sAHPs, we applied $\tau_{\text {noise }}=$ $10 \mathrm{~ms}$, finding a smaller gain increase (data not shown). However, slower fluctuations are likely to reduce gain, because they basically smooth the steady-state $f-I$ relationships.

\section{Mechanisms of noise effects}

Gain reduction in FS interneurons is simple. Without noise, $f-I$ relationships in these cells are discontinuous (Erisir et al., 1999; Tateno et al., 2004), with infinite gain at the current threshold. Noise causes voltage fluctuations that randomize threshold crossing, smooth the discontinuity, and reduce gain. The gain increase in pyramidal neurons is more mysterious. Our fundamental observation was that shunting by $G_{\text {asAHP }}$ reduced firing with low noise but not with high noise. As $G_{\text {asAHP }}$ increased with firing rate, suppression of firing with low noise strengthened, and thus noise increased gain. The basis of this stimulus-selective effect of somatic conductance remains unknown. Fellous et al. (2003) postulated that noise might increase gain when the balance of conductances cannot support rapid firing. This suggests that conductance could reduce firing with low noise by shunting spike-generating currents. However, reducing $\mathrm{Na}^{+}$current with TTX lowered the maximal firing rate but did not increase the additive or multiplicative effect of noise. Thus, generalized shunting of $\mathrm{Na}^{+}$current by $G_{\mathrm{sAHP}}$ cannot explain the gain increase. Another possibility is that $G_{\text {sAHP }}$ may reduce faster AHPs that promote firing with low noise.

The average gain increase was greater in cells with large native sAHPs than in cells with asAHPs of similar amplitude, suggesting that a somatic sAHP may not reproduce the full effect of the native sAHP. Spatial factors may affect the gain increase and its modulation by $G_{\text {sAHP. }} \mathrm{Na}^{+}$and $\mathrm{Ca}^{2+}$ spikes generated in apical dendrites (Kim and Connors, 1993; Reuveni et al., 1993; Yuste et al., 1994; Schiller et al., 1997; Stuart et al., 1997; Schwindt and Crill, 1999; Larkum et al., 1999) might cause noise to increase gain in some pyramidal neurons. Noisy current injected into the distal apical dendrite of layer 5 pyramidal cells increases gain for

$\leftarrow$

stimulus fluctuation to fire, and its gain increases with noise amplitude. $\boldsymbol{B}$, A pyramidal neuron (layer 2/3) with a large SAHP fires continuously during DC stimuli, but its gain is increased by noise. C, A pyramidal neuron with a small sAHP (layer 5) shows little gain change by noise. $\boldsymbol{D}, \mathrm{An}$ FS interneuron exhibits gain reduction by noise. $\boldsymbol{E}$, An ideal differentiator (with rectified output) shows an increase in firing rate with noise amplitude. Similar behavior occurs primarily at high mean current in gain-increasing neurons and at low mean current in gain-reducing cells. $\boldsymbol{F}, \mathrm{An}$ ideal temporal integrator fires at an average rate that is unaffected by input noise. The pyramidal neuron with a small SAHP is the cell closest to this ideal. 
a concurrent somatic stimulus by triggering dendritic $\mathrm{Ca}^{2+}$ spikes and subsequent burst firing at the soma (Larkum et al., 2004). During somatic stimuli, combining high DC current with large noise fluctuations may favor this process. Depolarization of the proximal apical dendrite (likely caused by DC current) favors back- and forward-propagation of spikes (Larkum et al., 2001), whereas highfrequency clusters of back-propagating spikes (most frequent with high DC and noise) trigger spike generation in the distal dendrite (Larkum et al., 1999; Williams and Stuart, 2000). Although dendritic processing is beyond the scope of this study, the loss of sensitivity to somatic shunting that we observed with high noise is consistent with spike initiation at an electrotonically distant site.

Our studies used simple current stimuli rather than naturalistic conductance input. Experiments and modeling have shown that rapid membrane potential fluctuations regulate gain (Chance et al., 2002; Mitchell and Silver, 2003). Because qualitatively similar voltage excursions are produced by current noise or conductance noise, we chose to inject fluctuating current to study the effect of noise on gain, isolated from the subtractive effect of conductance on the $f-I$ relationship (Holt and Koch, 1997). For inhibition, the reversal potential is close enough to the interspike voltage that inhibitory conductance of constant variance will cause current fluctuations that vary systematically across the interspike trajectory. This may affect gain modulation quantitatively (Fellous et al., 2003) but is unlikely to alter our results qualitatively. More critical aspects of natural input may be high average conductance (Destexhe and Paré, 1999), distribution of input to the dendrites, and complex temporal patterns. Future studies are required to investigate how gain depends on multiple parameters that characterize realistic input.

\section{Implications for synchrony coding}

Synchronous firing of cortical neurons occurs in vivo and may promote signal propagation (Reyes, 2003), feature grouping (Engel et al., 1991), attention (Steinmetz et al., 2000; Engel et al., 2001; Niebur et al., 2002), and short-term memory (TallonBaudry et al., 2001). A problem for synchrony coding is that the signal-to-background ratio for groups of synchronized neurons may fall when background cortical activity rises. This problem may be ameliorated by gain increases caused by input fluctuation (equivalent to greater fluctuation sensitivity during high average input) in pyramidal neurons with large sAHPs. Studies of model pyramidal neurons showed that input synchrony caused nearly Gaussian broadening of the subthreshold membrane potential distribution (Rudolph and Destexhe, 2001). Based on this, we predict that synchrony will have effects similar to those of Gaussian current noise. Thus, pyramidal neurons with large sAHPs may become more sensitive to synchrony during strong background excitation, helping to maintain the signal-to-background ratio. Two time scales are involved in this effect. Our results suggest that background excitation must occur for hundreds of milliseconds to cause adaptation that increases sensitivity to input fluctuation. The actual coincidence detection then occurs on the time scale of individual EPSPs, represented in our experiments by fast voltage fluctuations driven by stimulus noise. When coincidence detection occurs repeatedly during a period of increased input synchrony, it increases the average firing rate. During synaptic bombardment in vivo, the input resistance and membrane time constant of neocortical pyramidal neurons are reduced (Destexhe and Paré, 1999). This should increase the temporal precision of coincidence detection.

We predict that input synchrony will usually also increase firing of FS interneurons, because the relatively low firing rates observed during sensory stimulation (Azouz et al., 1997; Contreras and Palmer, 2003) suggest that these cells normally operate below their current threshold. In this case, input synchronization will trigger a barrage of inhibition that quickly limits the increase in network activity. This mechanism may sharpen the timing of synchronous packets of activity as they travel across the cortex. During very strong, sustained excitation, FS interneurons may be driven beyond threshold and fire rapidly regardless of synchrony. The "fail-safe" mechanism provided by the type II $f-I$ relationship of these cells may normally help to control cortical activity. However, in pathological conditions when suprathreshold inhibition is insufficient, the imbalance between excitation and inhibition may be worsened by input synchrony, which stimulates firing of pyramidal neurons but cannot increase the suprathreshold output of FS interneurons. This imbalance may allow highfrequency synchronous activity that occurs in focal-onset epilepsy to spread easily through the neocortex.

\section{Implications for gain control}

A variety of in vivo studies have found multiplicative effects on firing rate during changes in attention or behavioral state (McAdams and Maunsell, 1999; Treue and Martinez-Trujillo, 1999; Salinas and Thier, 2000). Several synaptic mechanisms have been proposed, including background noise, inhibitory synchrony, and inhibition. In their studies of layer 5 pyramidal neurons, Chance et al. (2002) found that background synaptic input, or increased input variance with constant conductance, reduced gain. Because synchronization of synaptic input increases input variance, it was surprising to learn that synchronizing inhibitory conductances at gamma frequency increased gain in layer 5 pyramidal cells under some conditions (Tiesinga et al., 2004a,b). Based on our results, we suspect that some differences between these studies may reflect the types of pyramidal neurons sampled rather than the stimulus waveforms. Finally, two mechanisms were described by which inhibition could reduce gain. In cerebellar granule cells, which receive a few powerful excitatory inputs, inhibition reduces gain by scaling the large, input frequencydependent voltage fluctuations produced by the EPSC train (Mitchell and Silver, 2003). In pyramidal neurons of weakly electric fish, dendritic inhibition reduces gain by shunting afterdepolarizations caused by action potential back-propagation (Mehaffey et al., 2005).

These studies suggest that background input has positive and negative effects on gain. Our results indicate that positive gain modulation may occur when pyramidal neurons with large sAHPs receive noisy background input near the soma. Gain increases may be greater when input arrives at distal apical dendrites (Larkum et al., 2004). In contrast, background input will likely reduce gain in FS interneurons, by the noise effect that we observed and perhaps the inhibitory mechanism of Mitchell and Silver (2003). If higher cortical areas that regulate attention show increased activity or synchrony before stimulus onset, input from these areas may increase network sensitivity by positive effects on pyramidal neurons and negative effects on sign-reversing FS interneurons.

\section{References}

Akemann W, Zhong Y-M, Ichinohe N, Rockland KS, Knöpfel T (2004) Transgenic mice expressing a fluorescent in vivo label in a distinct subpopulation of neocortical layer 5 pyramidal cells. J Comp Neurol 480:72-88.

Azouz R, Gray CM, Nowak LG, McCormick DA (1997) Physiological prop- 
erties of inhibitory interneurons in cat striate cortex. Cereb Cortex 7:534-545.

Benda J, Herz VM (2003) A universal model for spike-frequency adaptation. Neural Comput 15:2523-2564.

Carr CE, Konishi M (1990) A circuit for detection of interaural time differences in the brain stem of the barn owl. J Neurosci 10:3227-3246.

Chance F, Abbott L, Reyes A (2002) Gain modulation from background synaptic input. Neuron 35:773-782.

Contreras D, Palmer L (2003) Response to contrast of electrophysiologically defined cell classes in primary visual cortex. J Neurosci 23:6936-6945.

Cox CL, Metherate R, Ashe JH (1994) Modulation of cellular excitability in neocortex: muscarinic receptor and second messenger-mediated actions of acetylcholine. Synapse 16:123-136.

Destexhe A, Paré D (1999) Impact of network activity on the integrative properties of neocortical pyramidal neurons in vivo. J Neurophysiol 81:1531-1547.

Engel AK, Konig P, Singer W (1991) Direct physiological evidence for scene segmentation by temporal coding. Proc Natl Acad Sci USA 88:9136-9140.

Engel AK, Fries P, Singer W (2001) Dynamic predictions: oscillations and synchrony in top-down processing. Nat Rev Neurosci 2:704-716.

Erisir A, Lau D, Rudy B, Leonard CS (1999) Function of specific $\mathrm{K}^{+}$channels in sustained high-frequency firing of fast-spiking neocortical interneurons. J Neurophysiol 82:2476-2489.

Fellous J-M, Rudolph M, Destexhe A, Sejnowski TJ (2003) Synaptic background noise controls the input/output characteristics of single cells in an in vitro model of in vivo activity. Neuroscience 122:811-829.

Fleidervish I, Friedman A, Gutnick MJ (1996) Slow inactivation of current and slow cumulative spike adaptation in mouse and guinea-pig neurones in slices. J Physiol (Lond) 493:83-97.

Foehring RC, Schwindt PC, Crill WE (1989) Norepinephrine selectively reduces slow $\mathrm{Ca}^{2+}$ - and $\mathrm{Na}^{+}$-mediated $\mathrm{K}^{+}$currents in cat neocortical neurons. J Neurophysiol 61:245-256.

Franceschetti S, Sancini G, Panzica F, Radici C, Avanzini G (1998) Postnatal differentiation of firing properties and morphological characteristics in layer $\mathrm{V}$ pyramidal neurons of the sensorimotor cortex. Neuroscience 83:1013-1024.

Gerstner W, Kistler W (2002) Spiking neuron models: single neurons, populations, plasticity. Cambridge, UK: Cambridge UP.

Gottlieb JP, Keller A (1997) Intrinsic circuitry and physiological properties of pyramidal neurons in rat barrel cortex. Exp Brain Res 115:47-60.

Grande LA, Kinney GA, Miracle GL, Spain WJ (2004) Dynamic influences on coincidence detection in neocortical pyramidal neurons. J Neurosci 24:1839-1851.

Harris RJ, Symon L, Branston NM, Bayhan M (1981) Changes in extracellular calcium activity in cerebral ischaemia. J Cereb Blood Flow Metab 1:203-209.

Holt GR, Koch C (1997) Shunting inhibition does not have a divisive effect on firing rates. Neural Comput 9:1001-1013.

Jeffress L (1948) A place theory of sound localization. J Comp Physiol Psychol 61:468-486.

Kim HG, Connors BW (1993) Apical dendrites of the neocortex: correlation between sodium- and calcium-dependent spiking and pyramidal cell morphology. J Neurosci 13:5301-5311.

Kuba H, Yamada R, Fukui I, Ohmori H (2005) Tonotopic specialization of auditory coincidence detection in nucleus laminaris of the chick. J Neurosci 25:1924-1934.

La Camera G, Rauch A, Lüscher H-R, Senn W, Fusi S (2004) Minimal models of adapted neuronal response to in vivo-like input currents. Neural Comput 16:2101-2124.

Larkman A, Mason A (1990) Correlations between morphology and electrophysiology of pyramidal neurons in slices of rat visual cortex. I. Establishment of cell classes. J Neurosci 10:1407-1414.

Larkum ME, Zhu JJ, Sakmann B (1999) A new cellular mechanism for coupling inputs arriving at different cortical layers. Nature 398:338-341.

Larkum ME, Zhu JJ, Sakmann B (2001) Dendritic mechanisms underlying the coupling of the dendritic with the axonal action potential initiation zone of adult rat layer 5 pyramidal neurons. J Physiol (Lond) 533:447-466.

Larkum ME, Senn W, Lüscher H-R (2004) Top-down dendritic input increases the gain of layer 5 pyramidal neurons. Cereb Cortex 14:1059-1070.
Lorenzon NM, Foehring RC (1993) The ontogeny of repetitive firing and its modulation by norepinephrine in rat neocortical neurons. Brain Res Dev Brain Res 73:213-223.

Madeja M (2000) Do neurons have a reserve of sodium channels for the generation of action potentials? A study on acutely isolated CA1 neurons from the guinea-pig hippocampus. Eur J Neurosci 12:1-7.

Madison DV, Nicoll RA (1984) Control of the repetitive discharge of rat CA1 pyramidal neurons in vitro. J Physiol (Lond) 354:319-331.

Mainen ZF, Sejnowski TJ (1995) Reliability of spike timing in neocortical neurons. Science 268:1503-1506.

Mason A, Larkman A (1990) Correlations between morphology and electrophysiology of pyramidal neurons in slices of rat visual cortex. II. Electrophysiology. J Neurosci 10:1415-1428.

Massimini M, Amzica F (2001) Extracellular calcium fluctuations and intracellular potentials in the cortex during the slow sleep oscillation. J Neurophysiol 85:1346-1350.

McAdams CJ, Maunsell JHR (1999) Effects of attention on orientationtuning functions of single neurons in macaque cortical area V4. J Neurosci 19:431-441.

Mehaffey WH, Doiron B, Maler L, Turner RW (2005) Deterministic multiplicative gain control with active dendrites. J Neurosci 25:9968-9977.

Mitchell SJ, Silver RA (2003) Shunting inhibition modulates neuronal gain during synaptic excitation. Neuron 38:433-445.

Niebur E, Hsiao SS, Johnson KO (2002) Synchrony: a neuronal mechanism for attentional selection? Curr Opin Neurobiol 12:190-194.

Poliakov AV, Powers RK, Sawczuk A, Binder MD (1996) Effects of background noise on the response of rat and cat motoneurons to excitatory current transients. J Physiol (Lond) 495:143-157.

Rauch A, La Camera G, Lüscher H-R, Senn W, Fusi S (2003) Neocortical pyramidal cells respond as integrate-and-fire neurons to in vivo-like input currents. J Neurophysiol 90:1598-1612.

Reuveni I, Friedman A, Amitai Y, Gutnick MJ (1993) Stepwise repolarization from $\mathrm{Ca}^{2+}$ plateaus in neocortical pyramidal cells: evidence for nonhomogeneous distribution of HVA $\mathrm{Ca}^{2+}$ channels in dendrites. J Neurosci 13:4609-4621.

Reyes AD (2003) Synchrony-dependent propagation of firing rate in iteratively constructed networks in vitro. Nat Neurosci 6:593-599.

Reyes AD, Rubel EW, Spain WJ (1996) In vitro analysis of optimal stimuli for phase-locking and time-delayed modulation of firing in avian nucleus laminaris neurons. J Neurosci 16:993-1007.

Rudolph M, Destexhe A (2001) Do neocortical neurons display stochastic resonance? J Comput Neurosci 11:19-42.

Salinas E, Thier P (2000) Gain modulation: a major computation principle of the central nervous system. Neuron 27:15-21.

Schiller J, Schiller Y, Stuart G, Sakmann B (1997) Calcium action potentials restricted to apical dendrites of rat neocortical pyramidal neurons. J Physiol (Lond) 505:605-616.

Schwindt P, Crill W (1999) Mechanisms underlying burst and regular spiking evoked by dendritic depolarization in layer 5 cortical pyramidal neurons. J Neurophysiol 81:1341-1354.

Schwindt P, O’Brien JA, Crill W (1997) Quantitative analysis of firing properties of pyramidal neurons from layer 5 of rat sensorimotor cortex. J Neurophysiol 77:2484-2498.

Schwindt PC, Spain WJ, Foehring RC, Chubb MC, Crill WE (1988) Slow conductances in neurons from cat sensorimotor cortex in vitro and their role in slow excitability changes. J Neurophysiol 59:450-467.

Schwindt PC, Spain WJ, Crill WE (1989) Long-lasting reduction of excitability by a sodium-dependent potassium current in cat neocortical neurons. J Neurophysiol 61:233-244.

Segundo JP, Moore GP, Stensaas LJ, Bullock TH (1963) Sensitivity of neurons in Aplysia to temporal pattern of arriving impulses. J Exp Biol 40:643-667.

Shu Y, Hasenstaub A, Badoual M, Bal T, McCormick DA (2003) Barrages of synaptic activity control the gain and sensitivity of cortical neurons. J Neurosci 23:10388-10401.

Slee SJ, Higgs MH, Fairhall AL, Spain WJ (2005) Two-dimensional time coding in the auditory brainstem. J Neurosci 25:9978-9988.

Spain WJ (1994) Serotonin has different effects on two classes of Betz cells from the cat. J Neurophysiol 72:1925-1937.

Steinmetz PN, Roy A, Fitzgerald PJ, Hsiao SS, Johnson KO, Niebur E (2000) Attention modulates synchronized neuronal firing in primate somatosensory cortex. Nature 404:187-190. 
Stuart G, Schiller J, Sakmann B (1997) Action potential initiation and propagation in rat neocortical pyramidal neurons. J Physiol (Lond) 505:617-632.

Tallon-Baudry C, Bertrand O, Fischer C (2001) Oscillatory synchrony between human extrastriate areas during visual short-term memory maintenance. J Neurosci 21:RC177(1-5).

Tang AC, Bartels AM, Sejnowski TJ (1997) Effects of cholinergic modulation on responses of neocortical neurons to fluctuating input. Cereb Cortex 7:502-509.

Tateno T, Harsch A, Robinson HPC (2004) Threshold firing frequencycurrent relationships of neurons in rat somatosensory cortex: type 1 and type 2 dynamics. J Neurophysiol 92:2283-2294.

Tiesinga PH, Fellous J-M, Salinas E, José JV, Sejnowski TJ (2004a) Synchronization as mechanism for attentional gain modulation. Neurocomputing 58-60:641-646.

Tiesinga PH, Fellous J-M, Salinas E, José JV, Sejnowski TJ (2004b) Inhibitory synchrony as a mechanism for attentional gain modulation. J Physiol (Paris) 98:296-314
Treue S, Martinez-Trujillo JC (1999) Feature-based attention influences motion processing gain in macaque visual cortex. Nature 399: $575-579$.

Villalobos C, Beique J-C, Gingrich JA, Andrade R (2005) Serotonergic regulation of calcium-activated potassium currents in rodent prefrontal cortex. Eur J Neurosci 22:1120-1126.

Williams SR, Stuart GJ (2000) Backpropagation of physiological spike trains in neocortical pyramidal neurons: implications for temporal coding in dendrites. J Neurosci 20:8238-8246.

Yuste R, Gutnick MJ, Saar D, Delaney KR, Tank DW (1994) $\mathrm{Ca}^{2+}$ accumulations in dendrites of neocortical pyramidal neurons: an apical band and evidence for two functional compartments. Neuron 13:23-43.

Zhang Z, Arsenault D (2005) Gain modulation by serotonin in pyramidal neurons of the rat prefrontal cortex. J Physiol (Lond) 566:379-394.

Zhang L, Weiner JL, Valiante TA Velumian AA, Watson PL, Jahromi SS, Schertzer S, Pennefather P, Carlen PL (1994) Whole-cell recording of the $\mathrm{Ca}^{2+}$-dependent slow afterhyperpolarization in hippocampal neurons: effects of internally applied anions. Pflugers Arch 426:247-53. 